\title{
1 Habitat generalists or specialists, insights from comparative genomic analyses of
}

\section{Thermosipho lineages}

3

4 Thomas H.A. Haverkamp ${ }^{1 *}$, Claire Geslin ${ }^{2,3,4}$, Julien Lossouarn ${ }^{2,3,4}$, Olga A.

5 Podosokorskaya ${ }^{5}$, Ilya Kublanov ${ }^{5,6}$, Camilla L. Nesb $\emptyset^{1,7}$

6

$7 \quad *$ Corresponding author

$8{ }^{1}$ Centre for Ecological and Evolutionary Synthesis, University of Oslo, Oslo, Norway

$9 \quad{ }^{2}$ Université de Bretagne Occidentale (UBO), Institut Universitaire Européen de la Mer

10 (IUEM) - UMR 6197, Laboratoire de Microbiologie des Environnements Extrêmes (LMEE),

11 rue Dumont d'Urville, F-29280 Plouzané, France.

$12{ }^{3}$ CNRS, IUEM - UMR 6197, Laboratoire de Microbiologie des Environnements Extrêmes

13 (LMEE), rue Dumont d'Urville, F-29280 Plouzané, France.

$14{ }^{4}$ Ifremer, UMR 6197, Laboratoire de Microbiologie des Environnements Extrêmes (LMEE),

15 Technopôle Pointe du diable, F-29280 Plouzané, France.

$16{ }^{5}$ Winogradsky Institute of Microbiology, Research Center of Biotechnology, Russian

17 Academy of Sciences, Moscow, Russia.

$18{ }^{6}$ Immanuel Kant Baltic Federal University, Kaliningrad, Russia.

$19{ }^{7}$ Department of Biological Sciences, University of Alberta, Edmonton, AB, Canada

20

21

22 Keywords: Extremophiles, hydrothermal vents, mobile DNA, speciation, Thermotogae,

23 Vitamine B12 


\section{Abstract}

Thermosipho species inhabit various extreme environments such as marine

27 hydrothermal vents, petroleum reservoirs and terrestrial hot springs. A 16S rRNA phylogeny

28 of available Thermosipho spp. sequences suggested habitat specialists adapted to living in

29 hydrothermal vents only, and habitat generalists inhabiting oil reservoirs, hydrothermal vents

30 and hotsprings. Comparative genomics and recombination analysis of the genomes of 15

31 Thermosipho isolates separated them into three species with different habitat distributions, the

32 widely distributed T. africanus and the more specialized, T. melanesiensis and T. affectus.

33 The three Thermosipho species can also be differentiated on the basis of genome content. For

34 instance the T. africanus genomes had the largest repertoire of carbohydrate metabolism,

35 which could explain why these isolates were obtained from ecologically more divergent

36 habitats. The three species also show different capacities for defense against foreign DNA. $T$.

37 melanesiensis and T. africanus both had a complete RM system, while this was missing in $T$.

38 affectus. These observations also correlated with Pacbio sequencing, which revealed a

39 methylated T. melanesiensis BI431 genome, while no methylation was detected among two $T$.

40 affectus isolates. All the genomes carry CRISPR arrays accompanied by more or less

41 complete CRISPR-cas systems. Interestingly, some isolates of both T. melanesiensis and T.

42 africanus carry integrated prophage elements, with spacers matching these in their CRISPR

43 arrays. Taken together, the comparative genomic analyses of Thermosipho spp. revealed

44 genetic variation allowing habitat differentiation within the genus as well as differentiation

45 with respect to invading mobile DNA that is present in subsurface ecosystems. 


\section{Introduction}

Bacteria of the genus Thermosipho belong to phylum Thermotogae and are found in

49 high temperature environments such as deep-sea hydrothermal vents, and subsurface oil

50 reservoirs (Antoine et al. 1997; Takai \& Horikoshi 2000; Dahle et al. 2008). There are

51 currently eight described Thermosipho species: T. africanus, T. activus, T. affectus, $T$.

52 atlanticus, T. geolei, T. globiformans, T. japonicus and T. melanesiensis (Mukherjee \&

53 Sengupta 2015). These are thermophilic, organotrophic, anaerobes fermenting various sugars

54 of different complexity (e.g. glucose, starch, cellulose, etc) and peptides. While the main

55 fermentation products of all species are $\mathrm{H}_{2}$ and $\mathrm{CO}_{2}$, species-specific production of

56 compounds such as acetate, lactate, ethanol or alanine have been described (Swithers et al.

57 2011).

58 Comparative genomic analyses of Thermotogae bacteria, including Thermosipho,

59 have revealed complex evolutionary histories with extensive horizontal gene transfer (HGT),

60 particularly involving members of the bacterial phylum Firmicutes and the Archaea domain

61 (Enright et al. 2002). Most of the unique genes with predicted functions in different

62 Thermotogae lineages are classified as being involved in metabolism and particularly genes

63 involved in carbohydrate transport and degradation are numerous (Nesbø et al. 2002;

64 Zhaxybayeva et al. 2009). In agreement with this, Thermotogae and Thermosipho species in

65 particular, are commonly distinguished by being able to grow on different substrates. For

66 instance, T. affectus and T. activus are able to degrade cellulose compounds, while others

67 cannot (e.g. T. africanus) (Podosokorskaya et al. 2014). T. japonicus is able to degrade casein

68 as the sole carbon source in conjunction with the electron acceptor thiosulfate $\left(\mathrm{Na}_{2} \mathrm{~S}_{2} \mathrm{O}_{3}\right)$

69 (Takai \& Horikoshi 2000). How such metabolic differences are encoded in the genomes and

70 what pathways are involved is unresolved. Furthermore, how do the genetic differences 
71 correlate with the diversity found in the Thermosipho genus and the ecosystems that they

72 occupy?

73 One feature of the Thermosipho genus that has been studied at the genome level is the

74 presence of the vitamine B12 synthesis pathway in several Thermosipho isolates, but is absent

75 in other Thermotogae (Swithers et al. 2011). The genes needed for the vitamin B12 pathway

76 were acquired horizontally from the phylum Firmicutes. The acquisition of novel genetic

77 material in this way allows prokaryotes to establish novel metabolic capacities and develop

78 specific adaptations which may lead to species differentiation and innovation (Koonin 2015).

79 In addition, HGT is suggested to be important in the long-term maintenance and repair of

80 genomic information, by replacing inactivated genes by active ones (Takeuchi et al. 2014).

81 HGT can take place via transformation (naked DNA), conjugation (plasmids), transduction

82 (viruses), or transposition (transposable elements) but also with gene transfer agents (GTA's),

83 nanotubes or membrane vesicles produced by the microorganisms themselves (Darmon \&

84 Leach 2014).

85 Although novel DNA may be beneficial to microorganisms (Darmon \& Leach 2014),

86 viruses (and many mobile elements) can be without doubt harmful for cells, and prokaryotes

87 have developed defense methods. Several mechanisms exist that regulate the activity of

88 mobile DNA inside the cell (Westra et al. 2012), such as the restriction-modification (RM)

89 system, abortive infection ( $\mathrm{ABi}$ ) mechanisms, the clustered regulatory interspaced short

90 palindromic repeats (CRISPR) system and the recently described bacteriophage exclusion

91 (BREX) system (Stern \& Sorek 2011; Goldfarb et al. 2015). CRISPRs seems to be

92 particularly important in thermophiles (Weinberger et al. 2012), and have been identified in

93 all Thermotogae genomes characterized to date including two Thermosipho genomes (Nesbø

94 et al. 2009; Zhaxybayeva et al. 2009). The CRISPR associated genes (cas-genes) are essential

95 for the adaptation step in the CRISPR defense system where spacers from invading DNA are 
96 acquired and inserted in the CRISPR array (Makarova et al. 2015). Interestingly, most of the

97 CRISPR associated genes (Cas) show evidence of HGT when comparing T. africanus to

98 Thermotoga maritima (Nesbø et al. 2009).

99 The well-studied bacterial RM system is almost universally found in both bacteria and

100 archaea (Roberts et al. 2010). The RM system uses methylation to distinguish between self

101 and foreign DNA, and is found in most bacterial genomes (Roberts et al. 2010; Vasu \&

102 Nagaraja 2013). The system works by protecting methylated DNA from restriction enzymes.

103 Those enzymes will therefore only degrade invading mobile DNA that is not methylated.

104 Although the RM system is well studied, it is only poorly characterized among the

105 Thermotogae species described so far (Xu et al. 2011). For the genus Thermosipho in

106 particular, it is still unclear if RM systems are present, functional, and how it is involved in

107 the maintenance of genome stability when these populations have a high quantity of HGT

108 acquired genes.

109 In light of the high numbers of horizontally acquired genes within the Thermotogae it

110 is interesting that within the species Thermotoga maritima we found highly similar genomes

111 (Nesbø et al. 2015). This is remarkable when considering the isolation sources of the different

112 strains (The Azores, Italy, Japan, Kuril Islands (Russia) and the North Sea), which span the

113 earth, and suggests high levels of gene flow between distant subpopulations and active

114 mechanisms to maintain highly similar genomes (Nesbø et al. 2015).

115 Here we present a comparative analysis of 15 Thermosipho genomes, thirteen of

116 which are novel sequences generated in this study. The isolates included in this analysis were

117 obtained from deep-sea hydrothermal vents and produced fluids from oil reservoirs. The

118 genomes fall into three well-defined lineages (or species) with isolates from the same sample

119 sites showing very high similarities to each other. We show that the three species differ in

120 genomic content with regard to metabolic systems involved in carbohydrate and coenzyme 
bioRxiv preprint doi: https://doi.org/10.1101/106989: this version posted Februarv 8. 2017. The copvriaht holder for this preprint (which was not certified by peer review) is the author/funder, who has granted bioRxiv a license to display the preprint in perpetuity. It is made available under aCC-BY-NC-ND 4.0 International license.

121 metabolism, CRISPR-cas and the RM system. In addition, we show that several of the

122 genomes contain prophages.

123

124 


\section{Materials \& Methods}

126 DNA extraction and genome sequencing.

12713 Thermosipho strains were cultured in a modified Ravot medium as previously described in

128 (Lossouarn et al. 2015) and used for total DNA extraction as described in (Charbonnier et al.

129 1992; Geslin et al. 2003). All strains, except T. africanus Ob7 were submitted for genome

130 sequencing at the Norwegian Sequencing Centre (NSC, Oslo, Norway). A 300 bp insert

131 paired end library was prepared using the genomic DNA sample prep kit (Illumina, San

132 Diego, CA, USA) for each DNA sample. The Library was spiked with phiX DNA.

133 Subsequently, all strains except Ob7 were sequenced on an Illumina MiSeq generating a

134 dataset of 250 bp paired end reads.

135 Strain Ob7 was sequenced at University of Alberta, Canada, using an Iontorrent

136 (Thermo Fisher Scientific, Waltham, MA, USA) approach. DNA was enzymatically sheared

137 using the Ion Shear Plus kit (Life Technologies, Carlsbad, CA, USA) then cloned using the

138 Ion Plus Fragment Library kit (Life Technologies) following the manufacturer's instructions.

139 The library was then sequenced on an Ion Torrent PGM using a 316D chip and 500 flows.

$140 \quad$ Four isolates (Thermosipho sp. 430, 431, 1063, 1070) were selected for long read

141 sequencing with the goal to complete the genomes and assess methylation status of the DNA.

142 DNA's were prepared following the Pacific Biosciences instructions and sequenced at the

143 NSC on a Pacbio RSII (Pacific Biosciences, Menlo Park, CA, USA).

144

145 Quality control and genome assembly

146 Pacbio sequencing of the strains 431, 1063 and 1070 produced libraries suitable for

147 genome assembly without the addition of Illumina paired-end reads. For all strains Pacbio

148 read filtering and error-correction were performed using version 2.1 of the Pacbio smrtportal 
149 (http://www.pacb.com/devnet/). Assembly and base modification detection were performed

150 using the RS_HGAP_Assembly.2 and RS_Modification_and_Motif_analysis protocols.

151 Overlapping regions between contigs were manually detected using a combination of

152 read mapping and subsequent visualization with IGV (v. 2.3.23) (Thorvaldsdottir et al. 2013).

153 This allowed us to inspect regions with low quality mappings (due to the presence of

154 duplicated regions), and similar gene annotations on both sides of a contig gap. Preliminary

155 annotations were prepared using Glimmer at the RAST server and inspected in the CLC Bio

156 main workbench (Overbeek et al. 2013). Bam files were generated by mapping MiSeq PE

157 reads using bwa version (v. 0.7.5a) to the annotated contigs (Li \& Durbin 2009) and by

158 converting sam files with Samtools (v. 0.1.19). Bam files were imported into the IGV viewer

159 together with the annotated contigs ( $\mathrm{Li}$ et al. 2009). This approach resulted in closed

160 chromosomal sequences.

161 For strain 430, we generated a combined assembly using high quality illumina MiSeq

162 reads and a smaller set of Pacbio reads (15594 subreads) in an assembly using Spades (v.

163 3.5.0.) (Bankevich et al. 2012) with kmer size set to 127. Low coverage contigs $(<2.0)$ were

164 discarded. The remaining contigs were checked in IGV for miss-assemblies using mapped

165 MiSeq and Pacbio reads and if detected contigs were discarded. Finally the contigs were

166 checked for unambiguously overlapping ends as described above and if detected the contigs

167 were combined.

168 The T. africanus Ob7 genome was assembled using NEWBLER v. 2.6 (Margulies et

169 al. 2005). The remaining strains, were assembled using CLC assembler v.7, Spades (v. 3.5.0.)

170 and Velvet (v 1.2.10) (Zerbino \& Birney 2008) (Table 1). Genome assemblies were compared

171 using REAPR (v1.0.16) and the most optimal assembly for each strain was selected for

172 genome annotation with the PGAP pipeline from NCBI (Hunt et al. 2013).

173 
174 I6S rRNA Phylogeny of Thermosipho species

175 Full-length 16S rRNA sequences were manually extracted from the annotated

176 Thermosipho genome assemblies generated in this study as well as publically available

177 genomes. Next we searched the SILVA database version SSU r122 for Thermosipho spp. 16S

178 rRNA sequences with the following setting: sequence length > $1300 \mathrm{bp}$, alignment quality >

179 80, pintail quality > 80 (Quast et al. 2013). Matching sequences were downloaded and added

180 to extracted 16S rRNA sequences from the de-novo sequenced genomes. Multiple identical

181 sequences from the same strain with different accession numbers (e.g. the four 16S rRNA

182 sequences of $T$. melanesiensis BI429, five $16 \mathrm{~S}$ rRNA sequences $T$. africanus TCF52B) are

183 represented by a single sequence in the dataset.

184 The NCBI non-redundant database was then queried using BLASTn (blast+ v 2.2.26

185 (Camacho et al. 2009)) with the 16S rRNA gene dataset described above, to identify

186 Thermosipho sp. like 16S rRNA sequences missed with the above methods. Additional full-

187 length sequences were downloaded from Genbank and combined with the de-novo / SILVA

188 16S rRNA sequences.

189 The final 16S rRNA gene alignment consisted of Thermosipho sequences combined

190 with outgroup sequences from other Thermotogales species. The resulting alignment was

191 used to build phylogenies using Maximum Likelihood as implemented in MEGA 6.0 (Tamura

192 et al. 2013). and the General Time Reversible (GTR) model (G+I, 4 categories ) as suggested

193 by JModelTest v. 2.1.7 (Darriba et al. 2012).

194

195 Pangenome analysis

196 Blast Ring genome plots were generated using BRIG version 0.95 (Alikhan et al.

197 2011) running Blast+ version 2.2.28 (Camacho et al. 2009) with the following set up. The

198 nucleotide sequence of one of the 15 Thermosipho genomes was used to create the blast- 
199 database with default settings. Nucleotide sequences of all coding genes were extracted from 200 each genome (NCBI Genbank annotation) using CLC Main workbench Version 6.8.3 and 201 were used for BLASTn analysis in BRIG with the following settings: max_target_seqs: 1; 202 max e-value cut-off: $1.0^{-4}$. Alignments with a minimum of $70 \%$ similarity were visualized 203 with BRIG. The same procedure was used for all genomes.

204 Complete chromosome sequences or contigs were uploaded for all 15 genomes to the 205 Panseq 2.0 server (https://lfz.corefacility.ca/panseq/) for pangenome analysis (Laing et al. 206 2010). Sequence similarity cut-off (SC) was set at $70 \%$ to identify core-genome segments 207 and SNP's. We used the standard settings with Panseq except: percent sequence identity cut208 off set to $70 \%$, core genome threshold: 15 , BLAST word size: 11 . The final alignment of the 209 single nucleotide polymorphisms (SNPs) was loaded into splitstree and visualized as an 210 unrooted phylogeny using the neighbor network algorithm (Huson \& Bryant 2006)

211 Ten genome sequences (none-closed genomes of the T. melanesiensis cluster were 212 excluded, due to high sequence similarity) were aligned with progressiveMauve (Mauve (v.

213 2.3.1) (Darling et al., 2010)) using T. africanus H17ap60344 set as the reference and 214 automatically calculated seed weights and minimum Locally Colinear Blocks (LCB) scores.

215 Gaps were removed and the edited LCBs were concatenated in Geneious 8

216 (www.geneious.com). Recombination analysis of the concatenated alignment was done in 217 LikeWind (Archibald \& Roger 2002a; 2002b) using the maximum likelihood tree calculated 218 in PAUP* version 4.0b10 (Swofford 2002) under a GTR $+\Gamma+\mathrm{I}$ model as the reference tree.

219 Pairwise tetranucleotide frequency correlation coefficients (TETRA) and Average

220 Nucleotide identity (ANI) were calculated using the JspeciesWS webtool

221 (http://jspecies.ribohost.com/jspeciesws/) (Richter \& Rosselló-Mora 2009; Goris et al. 2007).

222 The pair-wise TETRA values were visualized with $\mathrm{R}$ (version 3.2.1) using the heatmap.2 
223 function (Package gplots) and the Thermosipho genomes were clustered using Jaccard

224 distances based on pairwise TETRA values (Package Vegan. version 2.3-0).

225 The IMG/ER Pairwise ANI calculation was used to determine the number of shared

226 genes between each genome separately (Markowitz et al. 2009). The method uses pairwise

227 bidirectional best $\mathrm{nSimScan}$ hits where similar genes share a minimum of $70 \%$ sequence

228 identity with $70 \%$ coverage of the smaller gene. For each genome we calculated the fraction

229 of shared genes with all other genomes. Unique genes per genome were determined using the

230 IMG Phylogenetic profiler tool for single genes, where each genome was analyzed for the

231 presence of genes without any homologs in all other 14 genomes. The settings were:

232 minimum e-value of $1.0^{-5}$; min percent identity: $70 \%$; pseudogenes were excluded; the

233 algorithm was present/absent homologs. The same tool was used to identify the presence of

234 homologs shared with all genomes, and with only the genomes from the same cluster.

235

236 Functional comparison of genome

237 The 15 genomes were compared using the Clusters of Orthologous Genes (COGs)

238 annotations. A COG reference database (version 10) was downloaded from the STRING

239 database (http://string-db.org/). For each genome all protein sequences were aligned using

240 BlastP, with the settings: 1 target sequence; maximum e-value: $1.0 \mathrm{e}^{-20}$; database size $1.0^{7}$;

241 tabular output. Only hits to COG database sequences were retained when the alignment was

$242>=70 \%$ of the length of the longest protein sequence and were used to build a protein COG

243 classification table. The COG IDs were summarized by classifying them to any of the

244 available COG categories (ftp://ftp.ncbi.nih.gov/pub/wolf/COGs/COG0303/cogs.csv).

245 For the COG analysis of the species-specific genes, we used the results from the IMG

246 phylogenetic profiler tool to identify cluster specific genes. The COG classification table was

247 screened for cluster specific genes and summarized into COG categories. 
In order to statistically compare species differences of COG categories we normalized

249 counts by total COG gene annotations, giving relative abundances per genome. R (version

250 3.3.0) was used to identify COG categories that were significantly different between the three

251 species using the non-parametric Kruskal-Wallis test (p-value $<=0.01$ ). The R-package

252 ggplot2 (version 2.1.0) was used to generate the comparisons graphically.

253

\section{Horizontal gene transfer detection}

255 Genes putatively acquired by HGT were identified using HGTector (Zhu et al. 2014)

256 with BLASTp (blast+ v 2.2.26). The databaser.py script was used on 6 December 2015 to

257 download per species one representative proteome of all microorganisms from the NCBI

258 refseq database. We compared the predicted Thermosipho spp. protein sequences to the

259 reference database using the following BLAST cut-offs: E-value: $1.0^{-5}$, Percentage identity:

$26070 \%$, percentage coverage: $50 \%$, and a maximum of 100 hits were returned. To determine

261 which genes were putatively acquired by any of the strains we set the HGTector self group to

262 the genus Thermosipho (NCBI taxonomy ID: 2420) and the close group to either the family

263 Fervidobacteriaceae (NCBI taxonomy ID: 1643950), or the order Thermotogales (NCBI

264 taxonomy ID: 2419). HGTector then analyzes the blast output from each protein for hits

265 matching taxa belonging to either the self or close groups, or more distantly related taxa,

266 which is used to determine which genes have likely been acquired from taxa more distantly

267 related than the close group. When the close group was set to Fervidobacteriaceae, we

268 identified putative HGT genes specific for Thermosipo sp. but not found in

269 Fervidobacteriaceae species. This setting however, did not indicate putative HGT genes

270 derived from other families within the Thermotogales order or beyond.

271

272 Defense genes 
273 Using the defense genes list created by Makarova et al., ( 2011), we screened the IMG

274 genome Clusters of Orthologous Genes (COG) annotations for the presence of any COGs

275 involved in any of the mobile DNA defences (Makarova et al. 2011). We summarized the

276 identified COGs and distinguished between CRISPR-cas associated or restriction-

277 modification (RM) system genes.

278

279

Crispr-spacer analysis.

280 All genomes were uploaded to CRISPR finder (http://crispr.i2bc.paris-saclay.fr/) to

281 detect CRISPR-arrays (Grissa et al. 2007). CRISPR spacer sequences from each genome were

282 compared using BLASTn against all Thermosipho sp. spacer sequences using the following

283 settings: e-value cut-off: $1.0^{-5}$, database size: $1.0^{7}$, dust: no. The tabular blast results were

284 visualized with R-statistics using the Markov Cluster Algorithm (MCL) (v1.0) and Igraph

285 (v1.0.1) packages. Igraph was used for matrix construction. MCL was run using the matrix

286 with the inflation set to 1.4 and max iterations set to 100 (Enright et al. 2002).

287 In order to search for matching sequences within the genome but outside the CRISPR

288 arrays, e.g target genes, we masked all CRISPR arrays using maskfeat (EMBOSS v. 6.5.7

289 (Rice et al. 2000)). Next we ran BLASTn (v2.2.26+) using the spacers of each genome

290 against the own genome using the following settings: e-value cut-off: $1.0^{-5}$, database size:

$2911.0^{7}$, dust: no. CRISPR array spacers were also compared against the NCBI nucleotide

292 database to find other species with similar sequences. BLASTn was run with the settings: e-

293 value cut-off: $1.0^{-5}$, dust: no. Each genome was screened for the presence of prophages

294 (Supplementary information for details).

295

296 Vitamine $B_{12}$ pathway analysis 
297 The genes involved in the Vitamine $\mathrm{B}_{12}$ metabolism are found in four different gene

298 clusters (BtuFCD, Corriniod, Cobalamin, and SucCoA) in Thermosipho and can be regulated

299 by $B_{12}$ riboswitches (Swithers et al. 2011). All 15 genomes were screened for the presence of

300 Cobalamin specific riboswitches using Riboswitch scanner (Mukherjee \& Sengupta 2015).

301 This information was used to confirm the presence of the four gene clusters in each genome.

302 Next, we extracted the protein sequences from the T. melanesiensis BI429 genome involved

303 in $B_{12}$ metabolism (Swithers et al. 2011) and used them to identify homologous genes in all

304 Thermosipho genomes using tBLASTn with a maximum e-value $1.0^{-20}$.

305

306

Data desposition

307 All genomes were deposited in the Genbank database and their accession numbers are

308 found in Table 1. In addition all genomes were deposited in the IMG databases and are linked

309 to the NCBI accession numbers. The $16 \mathrm{~S}$ rRNA alignment is available upon request from the

310 corresponding author. 


\section{Results.}

313 Global isolation of the genus Thermosipho from hydrothermal vents and oilfields.

314 We screened the NCBI-non-redundant (nr) database using BLASTn with Thermosipho

315 16S rRNA genes as probes to assess how our genomic analyses span the available

316 environmental diversity of Thermosipho lineages. This analysis revealed that most lineages or

317 species, e.g. T. melanesiensis, T. affectus and T. africanus, are well covered by our genomic

318 analysis (Figure 1, Supplementary materials Figure S1). Nonetheless, there are several

319 lineages, including T. geolei, T. ferriphilus and T. activus, for which we do not have genomic 320 data yet.

321 Moreover, the 16S rRNA gene phylogeny suggests ecological differences between the 322 different lineages (Figure 1). T. africanus isolates appear to be habitat 'generalists' and have

323 been isolated and detected in oil reservoirs, marine hydrothermal vents and terrestrial hot

324 springs. In contrast the T. melanesiensis and T. affectus lineages appear to be more specialized 325 and have only been obtained from marine hydrothermal vents. Thus one interesting question 326 is if and how these different life styles are reflected in their genomes with regard to diversity 327 and genome content.

Genome overview

330 The current study added 13 new genomes, with different levels of completion, to the 331 two existing ones (Table 1). All genomes share a low GC content $(29.9 \%-32.7 \%)$.

332 Interestingly, the $T$. affectus genomes are the smallest in this dataset $(\approx 1.77 \mathrm{Mbp})$, while the

333 T. melanesiensis $(\approx 1.9 \mathrm{Mbp})$ and $T$. africanus $(\approx 2.0 \mathrm{Mbp})$ genomes are larger. 
336 Tetranucleotide frequencies can be used to calculate the genomic similarity between

337 bacterial isolates, where pairwise similarity is expressed as tetranucleotide frequency

338 correlation coefficients (TETRA) (Richter \& Rosselló-Mora 2009). The heatmap of the

339 TETRA values of the Thermosipho genomes indicated the presence of 3 groups with high

340 intra relatedness (TETRA > 0.99) (Figure 2). Interestingly, the T. africanus isolates show

341 more divergent genomes compared to the other two clusters. We obtained similar clustering

342 results when we calculated the pairwise Average Nucleotide Identities (ANI) between the

343 isolates (data not shown), with intracluster identities $>95 \%$ and intercluster identities $<90 \%$.

344 The core- and pangenome of the genus Thermosipho was estimated to be $1.4 \mathrm{Mbp}$ and

345 5.6Mbp, respectively (Panseq2 sequence identity cut-off (IC): 70\%). Splitstree networks

346 (Huson \& Bryant 2006) using different SC showed very little differences regardless of which

347 IC was used (data non shown). The unrooted neighbor network calculated from 427,560 core

348 SNPs is shown in Figure 3A. The network shows three branches for the three lineages with

349 few differences within each lineage, similar to the pattern shown in the 16S rRNA tree and 350 the TETRA heatmap.

351 Finally, we used the progressive Mauve aligner to extract Locally collinear blocks

352 (LCBs) from 10 representative Thermosipho genomes to build a concatenated alignment. The

353 phylogeny based on this alignment (Supplementary materials Figure S2A) showed a similar

354 pattern as when using single nucleotide polymorphisms (SNPs) (Figure 3A). The

355 concatenated Mauve alignment was used for recombination detection analysis using

356 LikeWind (Archibald \& Roger 2002b), which detected numerous recombination events

357 within each cluster. However, no recombination events were detected between the clusters

358 suggesting that the lineages do indeed correspond to three distinct species (Supplementary

359 materials Figure S2).

360 
361

362

363

364

365

366

367

368

369

370

371

372

373

374

375

376

377

378

379

380

381

382

383

384

385

\section{Core / Pan genes}

Using the IMG Pairwise ANI tool we obtained for each genome the number of genes shared with all other genomes (Figure 3B). This gave a similar pattern as obtain using TETRA, ANIb/m, with the presence of three clusters. Between the three clusters we found that less than $80 \%$ of the genes are shared between the species (IC: 70\%). These results suggest the presence of strain and species-specific genes in each of the Thermosipho isolates analyzed. A visual inspection of genome content using BRIG showed a similar pattern (Supplementary information; Supplementary materials Figure S3 (Alikhan et al. 2011). The genomes from the T. melanesiensis cluster are highly similar, with T. melanesiensis BI429 being the most divergent (strain-specific genes, $n=33$ ) and the others strain with just a few $(\mathrm{BI} 431, \mathrm{n}=4)$ or no strain-specific genes (Table 2, Table 3, Supplementary Materials Table S1). The remaining Thermosipho spp. genomes have few $(\mathrm{BI} 1063, \mathrm{n}=11)$ to many unique genes (H17ap60334, n=169) (Supplementary Materials Table S1).

Identification of species-specific genes indicated that each species-level lineage has a common set of genes not detected in the other strain clusters (Table 2). Using 70\% IC, the $T$. melanesiensis strains have 424 (+/- 1.2) specific genes (23.0\% of total), while the T. affectus and T. africanus have $350(+/-2)(20.2 \%)$ and $650(+/-11)(33.4 \%)$ cluster specific genes respectively (Table 2). Many of the species-specific genes are hypothetical proteins (26 to 45 $\%$ ). The T. africanus genomes have a larger proportion of species-specific genes in their genome compared to the other two species. Interestingly, when using a less stringent cut-off of $30 \%$, the number of species-specific genes is substantially reduced, e.g. species-specific genes in T. melanesiensis BI429 fall to 67 genes (3\%), and the proportion of strain specific genes decreases as well. Also here the T. africanus genomes have the most species-specific genes, while T. affectus isolates have the least (average 5,8 vs $3.0 \%$ of total genes per genome). This indicates that most of the species-specific genes have distantly related 
386 homologs in the other two species, possibly due to either sequence diversification, or

387 replacement by more distantly related homologs acquired by HGT.

388

389

Horizontal gene transfer

390 Interestingly, in several of the genomes of the T. africanus and T. affectus isolates we

391 detected blocks of co-localized variable genes (min - max cluster size: 4 - 31) unique for that

392 genome (Table 3). No such blocks were found between the highly similar T. melanesiensis

393 strains. Several of the larger blocks of strain specific genes encode integrated prophages ( $T$.

394 affectus BI1074, T. africanus H17ap60334) as they could be detected by at least one prophage

395 finding tools (Supplementary information, Supplementary materials Table S1). In addition,

396 when only one of the T. melanesiensis genomes was used to find unique genes, we detected

397 one large block consisting of a prophage as well. This prophage was present in all $T$.

398 melanesiensis isolates (Haverkamp et al., manuscript in preparation). The remaining clusters

399 encode genes encoding CRISPR-cas proteins (Table 3) and genes involved in various types of

400 cellular activities. Only a few clusters are dominated by hypothetical proteins (Supplementary

401 materials Table S1).

402 The co-localization of unique genes suggests acquisition by HGT for these clusters.

403 HGTector (Zhu et al. 2014) analysis suggested that between $4.0 \%$ (T. affectus BI1063) and

$4045.8 \%$ (T. africanus H17ap60344) of the genes in each genome have been acquired from

405 species not belonging to the Thermotogales by HGT (Table 2, Supplementary materials Table

406 S2). The majority of the putative HGT genes (average $\approx 85 \%$ ) showed similarity to genes

407 found in other orders within the Thermotogae, such as the Kosmotogales and the Petrotogales.

408 The remaining genes (average $\approx 15 \%$ ) were mainly shared between the Thermosipho genomes

409 and genomes of Firmicutes and Euryarchaeota (Supplementary materials Table S2). Within

410 each genome about $50 \%$ of the putative HGT genes belonged to the COG categories: 
411 "Carbohydrate transport and metabolism", "Energy production and conversion", or were not

412 assigned to a COG category (e.g. Hypothetical genes) (data not shown). The ratio between

413 these three categories was different for the three species, with T. africanus having more

414 carbohydrate genes, while T. affectus species had more unassigned genes. Interestingly, many

415 of the putative HGT genes could be identified in several Thermosipho genomes, which

416 indicates that the common ancestor of the Thermosipho isolates acquired most of the putative

417 HGT genes. Only a few putative HGT genes fall into the genome or species-specific gene

418 sets. This is due to the fact that most of these proteins have no high quality blastP match in

419 the genomes in the HGTector database and will therefore not classify as putative HGT.

420

Genome-wide comparisons of COG categories

422 In order to detect functional differences between the three species we compared their

423 genomic content using Clusters of Orthologous Genes (COGs) annotations (Figure 4). This

424 revealed $T$. africanus to have genomes with the highest absolute gene abundances for many

425 COG categories, which is due to the T. africanus genomes being larger. However, this effect

426 disappears for most categories when using relative abundances of all COGs (Figure 4A;

427 Supplementary Materials Table S3). The categories H, J, L, R and G had the largest relative

428 abundance differences between the three species ( $\mathrm{p} \leq 0.01$ for $\mathrm{H}, \mathrm{J}$ and $\mathrm{R}$ and $\mathrm{p} \leq 0.05$ for $\mathrm{G}$

429 and L). Several other categories (B, C, I, O) had highly significant relative abundances

430 differences $(\mathrm{p} \leq 0.01)$, but absolute values were either very low (B), and relative abundance

431 differences were not very large between the species, and within species they were very similar

432 (Supplementary Materials Table S3).

433 The largest COG category is made up of Category R (General function prediction

434 only), with the T. affectus genomes having most genes (Figure 4). Category $\mathrm{R}$ is also the

435 largest group among the species-specific genes (Figure 4B). These results are in line with the 
436 observation that on average $42.1 \%, 49.3 \%$ and $54.8 \%$ (T. africanus, T. affectus and T.

437 melanesiensis) of the species-specific genes lack COG annotations and are hypothetical

438 genes. Interestingly, the T. africanus genomes have more genes with COG categories

439 annotations, but they do show more genes with the COG category R. This difference could be

440 caused by the careful manual curation of the TCF52B genome (Nesbø et al. 2009).

441 The T. affectus genomes show a significantly $(\mathrm{p} \leq 0.01)$ lower relative abundance of

442 genes in category $\mathrm{H}$ (Coenzyme transport and metabolism category) (Figure 4A). Closer

443 inspection shows that the T. affectus genomes are lacking most of the genes (20 out of 22

444 genes) needed for corrinoid synthesis, except CobT and an ATP-binding protein (indicated as

445 ORF). A complete set of corrinoid synthesis genes are found in the genomes of T. africanus

446 and T. melanesiensis, and are essential for de novo vitamine $\mathrm{B}_{12}$ synthesis (Swithers et al.

447 2011) (Supplementary materials Figure S4). Interestingly, the cobalamide salvage pathway

448 gene cluster, which is needed for retrieving incomplete corrinoid molecules from the

449 environment, is present in the T. affectus genomes. This gene cluster is, however, missing its

450 CobT' gene. This suggests that the orphan CobT gene, presumably a remnant from the

451 missing corrinoid cluster, is now functioning in the cobalamide salvage pathway

452 (Supplementary materials Figure S4).

453 Large differences among the genomes were also seen for COG category G

454 (Carbohydrate transport and metabolism). In agreement with this, phenotypic differences in

455 carbohydrate metabolism is one of the main other features, to distinguish between the three

456 species (Podosokorskaya et al. 2011). Also for this category, we find that the T. africanus

457 genomes have relatively more genes than the other two species (Figure 4A). This difference is

458 even more pronounced for species-specific genes (Figure 4B), where T. africanus genomes

459 have more genes present in this category (Supplementary Materials Table S3). A screening of

460 the genomes using PFAM annotations and the carbohydrate database dbCAN (Yin et al. 
461 2012), showed a similar pattern as with the COG annotations (Supplementary information;

462 Supplementary materials Table S4). The T. affectus, T. melanesiensis and T. africanus

463 genomes contain on average: 16-17, 20 and 21-26 genes respectively that are involved in

464 breakdown of carbohydrates (Supplementary materials Table S4). Moreover, the families,

465 containing enzymes involved in breakdown of various beta-linked oligo- and polysaccharides

466 (eg. cellulose, xylan, laminarin, lichenan, mannans and chitin) were found exclusively among

467 the representatives of T. africanus. This shows, in line with the COG analysis, that the $T$.

468 africanus species might be more versatile with regard to carbohydrate uptake and metabolism.

469 When we compared the COG categories for the species-specific genes we found even

470 larger differences for many categories (Figure 4B). Since the T. africanus genomes have

471 almost twice as many species-specific genes compared to the other two species, they also

472 have proportionally more species-specific genes in most categories. For instance, for COG

473 category L (Replication, recombination and repair) we find large variation in the number of

474 genes among the three T. africanus strains, with TCF52B having relatively more of these

475 genes compared to the other genomes ( $8.7 \%$ vs 5.7\%). Examination of the genes assigned to

476 this category revealed that this difference is mainly due to the presence of 18 copies of

477 transposases in the TCF52B genome.

478

479 Defense genes.

480 Above we identified several interesting features of the Thermosipho genomes, where

481 some of the genomes have a large set of unique genes, contain large mobile elements, or have

482 many putative HGT genes. This suggests that the defense mechanisms against mobile DNA

483 might differ among the isolates. We therefore screened the annotated genomes for the

484 presence of COGs that are related to defense mechanisms (Makarova et al. 2011), resulting in 
485 a list of 44 COGs that could be classified into three clusters, restriction-modification (RM)

486 systems genes (12), CRISPR-cas genes (18) and other COG annotations (14) (Figure 5).

487 Overall, the T. affectus genomes and T. africanus TCF52B have the most CRISPR-cas

488 genes (Figure 5). Specifically, we observed that all the Thermosipho genomes contain cas10

489 / crm2 (COG1353), which indicates the usage of the type III CRISPR-cas system

490 (Supplementary materials Table S5) (Makarova et al. 2015). The cas10/crm2 (COG1353)

491 annotated genes are present at multiple loci in T. affectus and T. melanesiensis strains, but

492 only one copy is found in T. africanus isolates. For the proper functioning of the type III

493 system, crm6 (COG1604) is needed. However, this gene is missing in T. africanus

494 H17ap60334, suggesting an incomplete and possibly non-functioning CRISPR-cas system

495 (Makarova et al. 2015). Furthermore, the T. africanus H17ap60334 genome has a lower

496 number of CRISPR-cas genes compared to the other isolates (Figure 5; Supplementary

497 materials Table S5). All the T. melanesiensis strains (except BI431) and T. africanus strain

498 TCF52B also carry the type I CRISPR-cas system (marker gene: cas3 (COG1203)). This gene

499 is not detected in the T. affectus or T. africanus Ob7 and H17ap60334 genomes, suggesting

500 there are differences in the mechanism of the CRISPR-cas system both within and between

501 the Thermosipho isolates / species.

502 We also detect differences in RM systems-gene content. The T. affectus genomes

503 contain few RM system genes and the T. melanesiensis have the most (Figure 5;

504 Supplementary materials Table S5). For a functioning RM system both the methylase and

505 restriction enzymes are needed. The restriction enzymes are absent from the T. affectus

506 genomes, which suggest that this species does not possess a functional RM-system

507 (Supplementary materials Table S4). In contrast, we detected both type I, II and III restriction

508 enzymes and DNA methylases in the T. melanesiensis genomes. In the T. africanus isolates a

509 complete type II system is present in the genomes of strains Ob7 and H17ap60334. In 
510 addition, all the T. africanus strains have a complete type III RM system (Supplementary

511 materials Table S5).

512 In agreement with the distribution of RM-systems, Pacbio sequencing of $T$.

513 melanesiensis BI431 and T. affectus BI1063 and BI1070 revealed that strain BI431 was

514 methylated, while the two T. affectus genomes lacked methylation. The T. melanesiensis

515 BI431 methylation sites detected matched those predicted in the Rebase restriction database

516 (Roberts et al. 2015); both methyl-6-adenosine (m6A) and methyl-4-cytosine (m4C)

517 methylation were detected along the entire BI431 genome. The dominant methylation sites

518 indicate that methylation was mainly due to the type II and III systems (Table 4). We did not

519 perform Pacbio sequencing of the T. africanus genomes, but the presence of a type-III

520 methylase enzyme suitable for a functional RM-system suggests the possibility of a

521 methylated genome.

522

523 CRISPR array variation

524 Between four and six CRISPR arrays were detected in all the genomes, except for $T$.

525 africanus TCF52B, which contains 12 arrays (Table 2, Table 5, supplementary materials table

526 S6). The total number of spacers detected in all genomes was 1709 , with spacer count varying

527 between 54 (T. affectus BI1223) to 321(T. africanus TCF52B). All the spacers could be

528 clustered into 1001 different clusters, indicating that there are both shared and unique spacers.

529 For instance, the highly similar T. melanesiensis genomes all have 5 CRISPR arrays, with a

530 total of 681 spacers that form 92 clusters that are present in all T. melanesiensis genomes

531 (Supplementary material Figure S5A). The only difference observed between these genomes

532 was strain BI429 missing four spacers found in the other genomes. Interestingly, six of the 92

533 clusters have spacers from different arrays (Supplementary material Figure S5A). 
534 The other two species show much more diversity in comparison to T. melanesiensis,

535 within the spacer sequence content between the strains of the different species

536 (Supplementary material Figure S5 B and C). The T. affectus spp. CRISPR array spacers

537 ( $\mathrm{n}=412)$ fall into 366 clusters, while the T. africanus spp. CRISPR array spacers $(\mathrm{n}=616)$

538 form 543 clusters.

539 Comparing spacer sequences to the host genome (excluding CRISPR arrays, blastN e-

540 value cut-off: $1.0^{-5}$ ) revealed a small fraction of the spacers with matches within its host

541 genome (percentage identity 88-100\%) (Table 5). The T. affectus genome spacers did not

542 match with any region in the host genome. For the T. melanesiensis genomes one spacer

543 (array 2, spacer 5) matched one gene (e.g. T. melanesiensis BI429: Tmel_1466: hypothetical

544 protein) in all genomes ( $81.8 \%$ identity, 6 SNPs). This gene is located within a prophage

545 element consisting of 50 protein coding genes (Tmel_1439 : Tmel_1486) (Haverkamp et al.,

546 in prep). The relatively low similarity between the spacer and the gene sequence could

547 suggests that this gene is not or no longer a target sequence, but we can not exclude it (Cady

548 \& O'Toole 2011).

549 For the T. africanus genomes we detected one CRISPR spacer, shared by all three

550 genomes, which has a non-perfect match to the same genomic region. The spacer matches a

551 phospholipase / carboxylesterase gene (THA_1282 in strain TCF52B) with 89-92\% identity.

552 For T. africanus H17ap60334 we find three additional spacers with perfect matches in two of

553 its gene; two spacers target H17ap60334_04822 and one targets H17ap60334_04912. Closer

554 examination revealed that also these genes are part of a predicted prophage region

555 (Haverkamp et al., in prep.; Supplementary information).

556 Finally, we searched NCBI's non-redundant nucleotide database for matches to the

557 Thermosipho spacer sequences. This identified two identical $44 \mathrm{bp}$ spacers, one in $T$.

558 africanus H17ap60334 (array 2, spacer 7) and one in T. africanus TCF52B (array 5, spacer 
559 20) that matched a sequence in the genome of Pseudothermotoga elfii DSM 9442 (genbank

560 refseq ID: NC_022792). The identified region in that genome (bp 200095 - 200125) is a

561 CRISPR spacer sequence of 38bp, which is identical to the Thermosipho spacer for 31 bases.

562 Interestingly, the first six bases of the Pseudothermotoga spacer has no match to the

563 Thermosipho H17ap60334 and TCF52B spacer, while the last 12 bases of the Thermosipho

564 spacers have no match to the Pseudothermotoga spacer. This suggests the spacers in both

565 species were acquired independently, but that they match a similar sequence.

566 


\section{Discussion}

568 Bacterial genome stability and evolution are under influence of HGT, which, among

569 other things, may influence how quickly a new species will arise (Darmon \& Leach 2014).

570 For instance, low levels of DNA exchange, within species, will allow mutations to arise

571 quicker than homologous recombination can repair it leading to speciation events, while high

572 levels of within species DNA exchange, prevents strains from accumulating enough

573 mutations to differentiate (Lawrence \& Retchless 2009). High levels of HGT have previously

574 been observed for Thermotogae bacteria, in particular the Thermotoga genus, which is found

575 in high temperature ecosystems, comparable to those where Thermosipho occurs (Nelson et

576 al. 1999; Zhaxybayeva et al. 2009; Nesbø et al. 2015). Some of these habitats can be very

577 different, e.g. marine hydrothermal vents and deep subsurface oil reservoirs. It is however

578 unclear, how habitat-range influences genome structure and content, levels of homologous

579 recombination and HGT (and vice versa).

$580 \quad$ Here we shed light on these questions by analyzing multiple isolates of the

581 Thermotogae genus Thermosipho. The isolates were obtained from various ecosystems across 582 the globe (Table 1) and fall into 3 different lineages or species: T. melanesiensis, T.africanus 583 and T. affectus. T. melanesiensis and T. affectus isolates were only obtained from

584 hydrothermal vents from one specific geographical region, while T. africanus members have

585 been obtained from a wide range of geographical and ecologically different environments (oil

586 reservoirs, hydrothermal vents and terrestrial hot springs). This implies that the genus

587 Thermosipho has specialist and generalist species, with the latter being present in a wider

588 range of ecosystems.

589 Although the above observation may be partly due to sampling and cultivation bias,

590 comparison with 16S rRNA genes from environmental samples (Dahle et al. 2008;

591 Nakagawa:2006jr; Stevenson et al. 2011; Smith et al. 2017) also supports this view, where the 
592 two lineages restricted to hydrothermal vents from a distinct branch in the 16S rRNA tree

593 (Figure 1). The fact that these lineages are restricted to hydrothermal vents and appear to have

594 more limited geographic ranges, suggests that these are more specialized species in

595 comparison to species found on the other 16S rRNA tree branch. Interestingly, in addition to

596 oil reservoirs, Thermosipho sp. have also been detected in subsurface crustal fluids Smith et

597 al., (2016) and their amplicon 16S rRNA sequences align best with species of the "generalist"

598 branch of the 16S rRNA tree (Data not shown). These results suggest that Thermosipho

599 lineages are widespread in the subsurface and not restricted to oil reservoirs or hydrothermal

600 vents.

601 Another representative of the Thermotogae species, where ecology is suggested to be

602 important for differentiation, is Thermotoga maritima. For this lineage, similar ecology was

603 found to be more important than close geographical distance to maintain highly similar

604 genomes through extensive gene flow (Nesbø et al. 2015); genomes from the same type of

605 environment (i.e. oil reservoir or marine vent) were more similar to each other than

606 geographically close genomes from different types of environments (Nesbø et al. 2015).

607 As in T. maritima we found that within Thermosipho sp. gene flow appears to be

608 important for the maintenance of the three distinct lineages or species, as we observe high

609 levels of recombination within the three lineages investigated. However, we also see a clear

610 differentiation of the three species with no recombination between lineages. These results

611 were further supported by the pangenome analysis of the genus Thermosipho (Figure 3B).

612 Each lineage, or species, contained a set of species-specific genes that were at best only

613 distantly related to genes in the other lineages. These genes mark the species boundaries and

614 possibly contribute to niche differentiation between the different Thermosipho species. This

615 was especially clear from the analysis of genes involved in carbohydrate and coenzyme

616 metabolism (COG category $\mathrm{G}$ and $\mathrm{H})$. 
617 These carbohydrate and coenzyme metabolism genes are important for energy

618 production and central metabolism and could play a role in the niche differentiation of the

619 Thermosipho species. For instance, the T. affectus genome contains several genes with a

620 dependency for vitamin B12 (e.g. B12 dependent methionine synthase, ribonucleotide

621 reductase Class II)(Swithers et al. 2011). However, the absence of most genes needed for the

622 corrinoid synthesis (needed for de-novo Vitamin B12 synthesis) (Coenyzme category) in $T$.

623 affectus suggests that this organism can only rely on the recovery of Vitamin B12 precursor

624 molecules (Supplementary materials Figure S4). It is unclear how this affects its physiology

625 and ecology. It will however, certainly affect the type of environments it can inhabit and its

626 role and interaction with other species in the communities they are part of. Likewise, $T$.

627 africanus has more genes involved in carbohydrate metabolism, which suggests that this

628 species is more diverse with respect to which carbohydrate molecules it can utilize. This

629 seems to be in line with the literature, (Podosokorskaya et al. 2014; Dipasquale et al. 2014)

630 and it could be partly responsible for its wider distribution in different ecosystems.

631 It is notable, that the species with the largest, and also most variable genomes, have

632 the widest distribution, both geographically and ecologically. However, the difference in

633 genomic variation within three lineages is probably also partly due of the fact that the $T$.

634 africanus isolates were sampled from three different geographically separated populations,

635 while the T. melanesiensis isolates all originated from a single population sampled at the same

636 time from the same ecosystem. The T. affectus genomes originated from two geographically

637 close sites and show intermediate levels of variation (Table 1). These results suggest that

638 isolation by distance is an important factor for differentiation in Thermosipho sp., as found in

639 other thermophiles \{Mino:2017gj\}. However, since T. affectus and T. melanesiensis have not

640 been detected at other locations than the isolation sites described here, this may be an entirely

641 academic question for these species. 


\section{Dealing with invasive DNA}

644 Phages and transposons are known vectors of "foreign" DNA with possible deleterious

645 effects, therefore limiting their integration and activity is an essential survival strategy for

646 many, if not all, bacterial species (Stern \& Sorek 2011). Several mobile elements were

647 detected in the Thermosipho genomes. For instance, T. africanus TCF52B carries 18 copies of

648 a transposase (COG2801). Moreover, one T. africanus (H17ap60334), one T. affectus

649 (BI1074) and all the T. melanesiensis strains have a prophage integrated into their genomes

650 (Haverkamp et al., unpublished). The presence of prophages in Thermotogales species has

651 earlier only been described in the thermophile Marinitoga piezophila, and analysis of the

652 phage (named MPV1) genome suggested it has played an important role as a HGT vector

653 (Lossouarn et al. 2015). A large fraction of its genes show a close phylogenetic relationship

654 with Firmicutes, the Thermotogae's main HGT partner (Zhaxybayeva et al. 2009). The

655 identification of multiple phages in Thermosipho genomes further supports the idea that

656 phage particles could be the general intermediates in gene flow within and between species in

657 the subsurface (Labonté et al. 2015).

658 Nonetheless, phages can be detrimental for prokaryotic cells such as Thermosipho, so

659 mechanisms are in place in this genus to intercept incoming foreign DNA. These mechanisms

660 consist of the RM and the CRISPR-cas system, that both play a role in intercepting invasive

661 DNA. The presence of CRISPR-cas genes, which are involved in prokaryotic immunity,

662 among the species- and strain specific genes is no surprise since they have been identified

663 before on mobile elements such as transposons and phages (Sebaihia et al. 2006; Seed et al.

664 2013). One example of this is a mobile element in T. africanus TCF52B flanked by

665 transposase recognition sites, which contains CRISPR-cas genes (Nesbø et al. 2009). This 
666 further indicates that mobile elements are not always deleterious for the receiver, but they can

667 be a source of novel beneficial genetic material.

668 The comparative genome analysis shows that there are clear differences between the

669 three Thermosipho species in the completeness of the systems, which may have implications

670 for acquiring novel DNA via HGT or recombination. For instance, all isolates have the

671 CRISPR-cas system, but the number of genes per genome related to this system differs, and in

672 T. africanus H17ap60334 the CRISPR-cas system may not be complete enough to be

673 functional. On the other hand, in contrast to the two other species the RM system is

674 incomplete in $T$. affectus species and likely not functional, indicating that T. affectus isolates

675 only rely on the CRISPR-cas system for defense against foreign DNA.

676 The lack of a working RM system was confirmed through PacBio sequencing of

677 strains T. affectus BI1063 and T. affectus BI1070 that showed no methylation. Pacbio

678 sequencing of T. melanesiensis BI431 revealed a methylated genome supporting the presence

679 of a working RM system. The genome of the isolate and the integrated prophage were

680 methylated. One of the RM systems detected in T. melanesiensis BI431 is located in the

681 integrated prophage, but it is not the only system that is active. Both host and prophage

682 methylases are expressed and methylation is detected at sites specific for those methylases

683 (Table 4). The presence and activity of a methylase in the prophage genome is a well know

684 evasive mechanism deployed by phages to escape the host RM system (Stern \& Sorek 2011).

685 That the host RM system is active suggests that T. melanesiensis strains repeatedly

686 encounter mobile DNA / phages in their natural environment. This is also suggested by the

687 low similarity of one of the CRISPR array spacers with the prophage genome, which implies

688 that considerable divergence has occurred since the creation of the spacer and the integration

689 of the detected prophage. If the sequence match had been perfect, it would have been likely

690 that the prophage could not have integrated since the CRISPR machinery would have stopped 
691 it at the door. Another interesting observation was the presence of a spacer, in both $T$.

692 africanus strains TCF52B and H17ap60334, similar but not identical to a spacer in the

693 genome of Pseudothermotoga elfii DSM 9442. This suggests the presence in the subsurface

694 of a broad range phage infecting both species.

695 Taken together, the observations of the diversity of CRISPR-cas systems, RM

696 systems, and mobile elements (i.e. prophages and transposons) in Thermosipho, indicate that

697 mobile DNA, such as phages and transposons, frequently interact with these bacterial

698 genomes in the subsurface. Recently, it was shown that phages are dominant players in the

699 subsurface realm, influencing ecosystem function by interacting with their prokaryotic hosts

700 (Engelhardt et al. 2015). It also implies that mobile DNA plays an important role in shaping

701 Thermosipho populations and species in the subsurface.

702

\section{Conclusions}

704 Here we compared the genomes of fifteen different Thermosipho isolates and found that they

705 belong to three clearly separated lineages or species: T. affectus, T. africanus and $T$.

706 melanesiensis. Recombination detection showed very little interspecies gene flow, but high

707 intraspecies gene flow. This finding was supported by the presence of large groups of species-

708 specific gene sets, reflecting the metabolic differences between the species. The species-

709 specific genes sets may further be responsible for differences in distribution of these species

710 in various ecosystems such as hydrothermal vents and petroleum reservoirs. Our observations

711 suggest that genome similarity in this genus decreases with increasing distance. However,

712 additional genome sequences of Thermosipho isolates from different locations and lineages

713 within this genus are needed in order to confirm this. Our analysis also revealed that the

714 presence of prophage elements is not uncommon in these thermophiles. It also showed that

715 each of the species has a different capacity for dealing with incoming DNA from phages and 
716 other mobile elements, which also affects intra-species gene flow. The presence of multiple

717 prophage elements in several Thermosipho isolates suggests that the high fraction of

718 horizontally acquired genes is possibly due to ongoing warfare between bacteria and phages

719 in the subsurface. Finally, the presence of similar CRISPR spacers, in multiple species and

720 isolates indicates that phages in the subsurface have broad host ranges allowing for inter-

721 species gene flow. That could ultimately explain why many genes in Thermotogales genomes

722 show high similarity with genes found in Archaea or Firmicutes genomes.

723 


\section{Acknowledgements}

725 The work of THAH and CLN, was supported was funded by the Norwegian Research

726 Council (award 180444/V40). JL and CG were supported by Agence Nationale de la

727 Recherche (ANR) (ANR-12-BSV3-OO23-01). OAP and IVK were supported by the Russian

728 Science Foundation (RSF) grant \# 16-14-00121. We thank the Norwegian Sequencing Centre

729 for sequencing and support with the bioinformatics analysis. We thank Ifremer and chief

730 scientists of the French oceanographic cruises "Biolau" (1989), "Marvel" (1997) and "Atos"

731 (2001). Strains are available under request at the 'Souchothèque de Bretagne' (catalogue

732 LMBE) culture collection (http://www.univ.brest.fr/souchoteque/collection+LM2E).

733

734 


\section{References}

736 Alikhan N-F, Petty NK, Ben Zakour NL, Beatson SA. 2011. BLAST Ring Image Generator

737 (BRIG): simple prokaryote genome comparisons. BMC Genomics. 12:402. doi:

$738 \quad 10.1186 / 1471-2164-12-402$.

739 Antoine E et al. 1997. Thermosipho melanesiensis sp. nov., a new thermophilic anaerobic

740 bacterium belonging to the order Thermotogales, isolated from deep-sea hydrothermal vents

741 in the southwestern Pacific Ocean. Int. J. Syst. Bacteriol. 47:1118-1123. doi:

$742 \quad 10.1099 / 00207713-47-4-1118$.

743 Archibald JM, Roger AJ. 2002a. Gene conversion and the evolution of euryarchaeal

744 chaperonins: a maximum likelihood-based method for detecting conflicting phylogenetic

745 signals. J Mol Evol. 55:232-245. doi: 10.1007/s00239-002-2321-5.

746 Archibald JM, Roger AJ. 2002b. Gene duplication and gene conversion shape the evolution

747 of archaeal chaperonins. Journal of Molecular Biology. 316:1041-1050. doi:

748 10.1006/jmbi.2002.5409.

749 Bankevich A et al. 2012. SPAdes: a new genome assembly algorithm and its applications to

750 single-cell sequencing. Journal of Computational Biology. 19:455-477. doi:

$751 \quad 10.1089 / \mathrm{cmb} .2012 .0021$.

752 Cady KC, O'Toole GA. 2011. Non-identity-mediated CRISPR-bacteriophage interaction

753 mediated via the Csy and Cas3 proteins. J Bacteriol. 193:3433-3445. doi: 10.1128/JB.01411-

75410.

755 Camacho C et al. 2009. BLAST+: architecture and applications. BMC Bioinformatics.

756 10:421. doi: 10.1186/1471-2105-10-421.

757 Charbonnier F, Erauso G, Barbeyron T, Prieur D, Forterre P. 1992. Evidence that a plasmid

758 from a hyperthermophilic archaebacterium is relaxed at physiological temperatures. $\mathrm{J}$

759 Bacteriol. 174:6103-6108.

760 Dahle H, Garshol F, Madsen M, Birkeland N-K. 2008. Microbial community structure

761 analysis of produced water from a high-temperature North Sea oil-field. Antonie van

762 Leeuwenhoek. 93:37-49. doi: 10.1007/s10482-007-9177-z.

763 Darmon E, Leach DRF. 2014. Bacterial genome instability. Microbiol. Mol. Biol. Rev. 78:1764 39. doi: 10.1128/MMBR.00035-13.

765 Darriba D, Taboada GL, Doallo R, Posada D. 2012. jModelTest 2: more models, new

766 heuristics and parallel computing. Nat Meth. 9:772-772. doi: 10.1038/nmeth.2109.

767 Dipasquale L, Romano I, Picariello G, Calandrelli V, Lama L. 2014. Characterization of a

768 native cellulase activity from an anaerobic thermophilic hydrogen-producing bacterium

769 Thermosipho sp. strain 3. Ann Microbiol. 64:1493-1503. doi: 10.1007/s13213-013-0792-9.

770 Engelhardt T, Orsi WD, Jørgensen BB. 2015. Viral activities and life cycles in deep

771 subseafloor sediments. Environ Microbiol Rep. 7:868-873. doi: 10.1111/1758-2229.12316.

772 Enright AJ, Van Dongen S, Ouzounis CA. 2002. An efficient algorithm for large-scale 
773 detection of protein families. Nucleic Acids Res. 30:1575-1584. doi: 10.1093/nar/30.7.1575.

774 Geslin C et al. 2003. PAV1, the first virus-like particle isolated from a hyperthermophilic

775 euryarchaeote, "Pyrococcus abyssi". J Bacteriol. 185:3888-3894. doi:

$776 \quad 10.1128 / \mathrm{JB} .185 .13 .3888-3894.2003$.

777 Goldfarb T et al. 2015. BREX is a novel phage resistance system widespread in microbial

778 genomes. EMBO J. 34:169-183. doi: 10.15252/embj.201489455.

779 Goris J et al. 2007. DNA-DNA hybridization values and their relationship to whole-genome

780 sequence similarities. Int J Syst Evol Microbiol. 57:81-91. doi: 10.1099/ijs.0.64483-0.

781 Grissa I, Vergnaud G, Pourcel C. 2007. CRISPRFinder: a web tool to identify clustered

782 regularly interspaced short palindromic repeats. Nucleic Acids Res. 35:W52-7. doi:

783 10.1093/nar/gkm360.

784 Hunt M et al. 2013. REAPR: a universal tool for genome assembly evaluation. Genome Biol. 785 14:R47. doi: 10.1186/gb-2013-14-5-r47.

786 Huson DH, Bryant D. 2006. Application of phylogenetic networks in evolutionary studies.

787 Molecular Biology and Evolution. 23:254-267. doi: 10.1093/molbev/msj030.

788 Koonin EV. 2015. The turbulent network dynamics of microbial evolution and the statistical 789 tree of life. J Mol Evol. 80:244-250. doi: 10.1007/s00239-015-9679-7.

790 Labonté JM et al. 2015. Single cell genomics indicates horizontal gene transfer and viral 791 infections in a deep subsurface Firmicutes population. Front Microbiol. 6:349. doi:

$79210.3389 /$ fmicb.2015.00349.

793 Laing $\mathrm{C}$ et al. 2010. Pan-genome sequence analysis using Panseq: an online tool for the rapid 794 analysis of core and accessory genomic regions. BMC Bioinformatics. 11:461. doi:

$79510.1186 / 1471-2105-11-461$.

796 Lawrence JG, Retchless AC. 2009. The interplay of homologous recombination and 797 horizontal gene transfer in bacterial speciation. In: Horizontal gene transfer: genomes in 798 flux.Vol. 532 pp. 29-53. doi: 10.1007/978-1-60327-853-9_3.

$799 \mathrm{Li} \mathrm{H}$ et al. 2009. The sequence alignment/map format and SAMtools. Bioinformatics. 800 25:2078-2079. doi: 10.1093/bioinformatics/btp352.

801 Li H, Durbin R. 2009. Fast and accurate short read alignment with Burrows-Wheeler 802 transform. Bioinformatics. 25:1754-1760. doi: 10.1093/bioinformatics/btp324.

803 Lossouarn J et al. 2015. 'Ménage à trois': a selfish genetic element uses a virus to propagate 804 within Thermotogales. Environ. Microbiol. 17:3278-3288. doi: 10.1111/1462-2920.12783.

805 Makarova KS et al. 2015. An updated evolutionary classification of CRISPR-Cas systems.

806 Nat Rev Micro. 13:722-736. doi: 10.1038/nrmicro3569.

807 Makarova KS, Wolf YI, Snir S, Koonin EV. 2011. Defense islands in bacterial and archaeal

808 genomes and prediction of novel defense systems. J Bacteriol. 193:6039-6056. doi:

$809 \quad 10.1128 / J B .05535-11$. 
810 Margulies $\mathrm{M}$ et al. 2005. Genome sequencing in microfabricated high-density picolitre 811 reactors. Nature. 437:376-380. doi: 10.1038/nature03959.

812 Markowitz VM et al. 2009. IMG ER: a system for microbial genome annotation expert 813 review and curation. Bioinformatics. 25:2271-2278. doi: 10.1093/bioinformatics/btp393.

814 Mukherjee S, Sengupta S. 2015. Riboswitch Scanner: an efficient pHMM-based web-server 815 to detect riboswitches in genomic sequences. Bioinformatics. 32:776-778. doi:

816 10.1093/bioinformatics/btv640.

817 Nei M, Kumar S. 2000. Molecular evolution and phylogenetics. Oxford University Press: 818 New York.

819 Nelson KE et al. 1999. Evidence for lateral gene transfer between Archaea and bacteria from 820 genome sequence of Thermotoga maritima. Nature. 399:323-329. doi: 10.1038/20601.

821 Nesbø CL et al. 2015. Evidence for extensive gene flow and Thermotoga subpopulations in 822 subsurface and marine environments. ISME J. 9:1532-1542. doi: 10.1038/ismej.2014.238.

823 Nesbø CL et al. 2009. The genome of Thermosipho africanus TCF52B: lateral genetic 824 connections to the Firmicutes and Archaea. J Bacteriol. 191:1974-1978. doi:

$82510.1128 /$ JB.01448-08.

826 Nesbø CL, Nelson KE, Doolittle WF. 2002. Suppressive subtractive hybridization detects 827 extensive genomic diversity in Thermotoga maritima. J Bacteriol. 184:4475-4488. doi: 828 10.1128/JB.184.16.4475-4488.2002.

829 Overbeek R et al. 2013. The SEED and the Rapid Annotation of microbial genomes using 830 Subsystems Technology (RAST). Nucleic Acids Res. 42:D206-D214. doi:

831 10.1093/nar/gkt1226.

832 Podosokorskaya OA et al. 2014. Thermosipho activus sp. nov., a thermophilic, anaerobic, 833 hydrolytic bacterium isolated from a deep-sea sample. Int J Syst Evol Microbiol. 64:3307834 3313. doi: 10.1099/ijs.0.063156-0.

835 Podosokorskaya OA, Kublanov IV, Reysenbach A-L, Kolganova TV, Bonch-Osmolovskaya 836 EA. 2011. Thermosipho affectus sp. nov., a thermophilic, anaerobic, cellulolytic bacterium 837 isolated from a Mid-Atlantic Ridge hydrothermal vent. Int J Syst Evol Microbiol. 61:1160838 1164. doi: 10.1099/ijs.0.025197-0.

839 Quast C et al. 2013. The SILVA ribosomal RNA gene database project: improved data 840 processing and web-based tools. Nucleic Acids Res. 41:D590-6. doi: 10.1093/nar/gks1219.

841 Rice P, Longden I, Bleasby A. 2000. EMBOSS: the European Molecular Biology Open 842 Software Suite. Trends Genet. 16:276-277.

843 Richter M, Rosselló-Mora R. 2009. Shifting the genomic gold standard for the prokaryotic 844 species definition. Proc Natl Acad Sci U S A. 106:19126-19131. doi:

845 10.1073/pnas.0906412106.

846 Roberts RJ, Vincze T, Posfai J, Macelis D. 2010. REBASE--a database for DNA restriction 847 and modification: enzymes, genes and genomes. Nucleic Acids Res. 38:D234-6. doi: 
849 Roberts RJ, Vincze T, Posfai J, Macelis D. 2015. REBASE--a database for DNA restriction

850 and modification: enzymes, genes and genomes. Nucleic Acids Res. 43:D298-9. doi:

$851 \quad 10.1093 /$ nar/gku1046.

852 Sebaihia $\mathrm{M}$ et al. 2006. The multidrug-resistant human pathogen Clostridium difficile has a

853 highly mobile, mosaic genome. Nat Genet. 38:779-786. doi: 10.1038/ng1830.

854 Seed KD, Lazinski DW, Calderwood SB, Camilli A. 2013. A bacteriophage encodes its own

855 CRISPR/Cas adaptive response to evade host innate immunity. Nature. 494:489-491. doi:

$85610.1038 /$ nature11927.

857 Smith AR, Fisk MR, Thurber AR, Flores GE. 2017. Deep Crustal Communities of the Juan de 858 Fuca Ridge Are Governed by Mineralogy. Geomicrobiology journal. 34:147-156. doi:

859 10.1080/01490451.2016.1155001.

860 Stern A, Sorek R. 2011. The phage-host arms race: shaping the evolution of microbes.

861 Bioessays. 33:43-51. doi: 10.1002/bies.201000071.

862 Stevenson BS et al. 2011. Microbial communities in bulk fluids and biofilms of an oil facility

863 have similar composition but different structure. Environ. Microbiol. 13:1078-1090. doi:

864 10.1111/j.1462-2920.2010.02413.x.

865 Swithers KS et al. 2011. Vitamin B(12) synthesis and salvage pathways were acquired by 866 horizontal gene transfer to the Thermotogales. Genome Biology and Evolution. 4:730-739. 867 doi: 10.1093/gbe/evs057.

868 Swofford DL. 2002. PAUP*: Phylogenetic analysis using parsimony (*and other methods). 869 v.4.0b10. Sinauer \& Associates: Sunderland, Massachusetts.

870 Takai K, Horikoshi K. 2000. Thermosipho japonicus sp. nov., an extremely thermophilic 871 bacterium isolated from a deep-sea hydrothermal vent in Japan. Extremophiles. 4:9-17.

872 Takeuchi N, Kaneko K, Koonin EV. 2014. Horizontal gene transfer can rescue prokaryotes 873 from Muller's Ratchet: benefit of DNA from dead cells and population Subdivision. G3:

874 Genes| Genomes| Genetics. 4:325-339. doi: 10.1534/g3.113.009845/-/DC1.

875 Tamura K, Stecher G, Peterson D, Filipski A, Kumar S. 2013. MEGA6: Molecular

876 Evolutionary Genetics Analysis Version 6.0. Molecular Biology and Evolution. 30:2725-

877 2729. doi: 10.1093/molbev/mst197.

878 Thorvaldsdottir H, Robinson JT, Mesirov JP. 2013. Integrative Genomics Viewer (IGV):

879 high-performance genomics data visualization and exploration. Briefings in Bioinformatics.

880 14:178-192. doi: 10.1093/bib/bbs017.

881 Vasu K, Nagaraja V. 2013. Diverse functions of restriction-modification systems in addition 882 to cellular defense. Microbiol. Mol. Biol. Rev. 77:53-72. doi: 10.1128/MMBR.00044-12.

883 Weinberger AD, Wolf YI, Lobkovsky AE, Gilmore MS, Koonin EV. 2012. Viral diversity 884 threshold for adaptive immunity in prokaryotes. MBio. 3:e00456-12. doi:

885 10.1128/mBio.00456-12. 
886 Westra ER et al. 2012. The CRISPRs, they are a-changin': how prokaryotes generate adaptive

887 immunity. Annu. Rev. Genet. 46:311-339. doi: 10.1146/annurev-genet-110711-155447.

888 Xu Z, Han D, Cao J, Saini U. 2011. Cloning and characterization of the TneDI restriction: 889 modification system of Thermotoga neapolitana. Extremophiles. 15:665-672. doi:

890 10.1007/s00792-011-0397-9.

891 Yin Y et al. 2012. dbCAN: a web resource for automated carbohydrate-active enzyme

892 annotation. Nucleic Acids Res. 40:W445-W451. doi: 10.1093/nar/gks479.

893 Zerbino DR, Birney E. 2008. Velvet: algorithms for de novo short read assembly using de 894 Bruijn graphs. Genome Research. 18:821-829. doi: 10.1101/gr.074492.107.

895 Zhaxybayeva $\mathrm{O}$ et al. 2009. On the chimeric nature, thermophilic origin, and phylogenetic 896 placement of the Thermotogales. Proc Natl Acad Sci U S A. 106:5865-5870. doi:

897 10.1073/pnas.0901260106.

898 Zhu Q, Kosoy M, Dittmar K. 2014. HGTector: an automated method facilitating genome899 wide discovery of putative horizontal gene transfers. BMC Genomics. 15:717. doi:

900 10.1186/1471-2164-15-717.

901

902

903 
905 Table 1: Overview of Thermosipho genomes used in this study.

\begin{tabular}{|c|c|c|c|c|c|c|c|c|c|}
\hline T. genome & $\begin{array}{c}\text { NCBI } \\
\text { accession } \\
\text { number }\end{array}$ & $\begin{array}{c}\text { Nr of } \\
\text { contigs } \\
\#\end{array}$ & $\begin{array}{l}\text { Genome } \\
\text { size } \\
\text { (bp) }\end{array}$ & $\begin{array}{c}\text { GC } \\
\text { content } \\
(\%)\end{array}$ & $\begin{array}{l}\text { Sequence } \\
\text { technology }\end{array}$ & $\begin{array}{c}\text { Genome } \\
\text { coverage } \\
\S\end{array}$ & Isolation source & References & 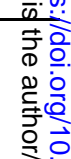 \\
\hline T. melanesiensis BI429*\& & NC_009616 & 1 & 1.915 .238 & 31.4 & 454 / Sanger & - & $\begin{array}{l}\text { Gills of mussel, Deep-sea H. vent, } \\
\text { Pacific Ocean, Lau Basin }\end{array}$ & \multirow{2}{*}{\multicolumn{2}{|c|}{ 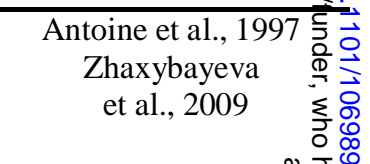 }} \\
\hline$T$. melanesiensis $430^{\&}$ & JYCX00000000 & 4 & 1.906 .053 & 31.5 & MiSeq & $243^{\mathrm{M}}$ & Gills of gastropod Deep-sea H. & & \\
\hline T. melanesiensis $431^{\&}$ & СР007389 & 1 & 1.915 .344 & 31.4 & Pacbio /MiSeq & $34^{\mathrm{P}} / 223^{\mathrm{M}}$ & Sample of active chimney & this study & \\
\hline T. melanesiensis $433^{\&}$ & JYCZ00000000 & 21 & 1.890 .575 & 32.6 & MiSeq & $256^{\mathrm{M}}$ & Gills of a mussel & & \\
\hline T. melanesiensis $434^{\&}$ & JYDA00000000 & 22 & 1.892 .506 & 32.7 & MiSeq & $234^{\mathrm{M}}$ & & & \\
\hline$T$. melanesiensis $487^{\star}$ & JYDB00000000 & 21 & 1.890 .479 & 32.6 & MiSeq & $239^{\mathrm{M}}$ & Sample of active chimney & & \\
\hline T. affectus $1063 \%$ & СР007223 & 1 & 1.766 .633 & 31.5 & Pacbio /MiSeq & $38^{\mathrm{P}} / 304^{\mathrm{M}}$ & Deep sea H. vent, Atlantic ocean & \multicolumn{2}{|c|}{ Wery et al., 2002용 } \\
\hline T. affectus $1070 \%$ & СР007121 & 1 & & 31.5 & Pacbio /MiSeq & $37^{\mathrm{P}} / 257^{\mathrm{M}}$ & Menez-Gwen hydrothermal field & this study & \\
\hline T. affectus $1074 \%$ & LBEX00000000 & 20 & $1 . \overline{7} 8 \overline{8} .30 \overline{3}$ & 33.3 & MiSeq & $258^{\mathrm{M}}$ & Menez-Gwen hydrothermal field & this study & \\
\hline T. affectus ik275mar & LBFC00000000 & 27 & 1.771 .018 & 32.6 & MiSeq & $256^{\mathrm{M}}$ & Rainbow H.vent field & \multicolumn{2}{|c|}{ 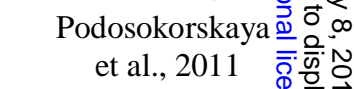 } \\
\hline T. affectus sp. $1223^{\infty}$ & LBEY00000000 & 39 & 1.767 .555 & 32.1 & MiSeq & $226^{\mathrm{M}}$ & Rainbow H.vent field & this study & \\
\hline T. africanus ob7 & $?$ & 23 & 1.933435 & 32.7 & Ion Torrent & - & Tadjoura gulf Hydrothermal springs & Huber et al,.1989 & \\
\hline T. africanus H17ap60334 & AJIP0100000 & 49 & 2.083 .551 & 29.9 & 454 / Sanger & 310 & $\begin{array}{l}\text { production water Hibernia oil } \\
\text { platform }\end{array}$ & this study & \\
\hline T. africanus TCF52B* & NC_011653 & 1 & 2.016 .657 & 30.8 & Sanger & - & $\begin{array}{l}\text { production water Troll C oil } \\
\text { platform, North Sea }\end{array}$ & $\begin{array}{l}\text { Dahle et al., } 2008 \\
\text { Nesbø et al., } 2009\end{array}$ & \\
\hline $\begin{array}{l}\text { * Not sequenced during } \\
{ }^{\&} \text { Strains } 429 \text { to } 487 \text { iso }\end{array}$ & ed during Oce & raphic & e Biola & cific $\mathrm{C}$ & an, Lau Bas & Deep-se & ydrothermal vent & 39 & 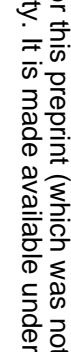 \\
\hline
\end{tabular}


$909{ }^{\infty}$ Isolated during Oceanographic cruise Atos, Atlantic ocean, Rainbow, Deep sea Hydrothermal vent.

910 \# Genomes with 1 contig were closed

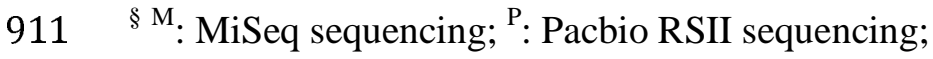


913 Table 2. Overview of genome content with a focus on mobile DNA defence systems and mobile elements

\begin{tabular}{|c|c|c|c|c|c|c|c|c|c|}
\hline Genome & Closed & ORFs & $\begin{array}{c}\text { Species- } \\
\text { specific } \\
\text { ORFs }\end{array}$ & $\begin{array}{c}\text { Strain } \\
\text { specific } \\
\text { ORFs }\end{array}$ & $\begin{array}{c}\text { Putative } \\
\text { HGT } \\
\text { ORFs }\end{array}$ & $\begin{array}{c}\text { Defence } \\
\text { genes }\end{array}$ & $\begin{array}{c}\text { CRISPR } \\
\text { arrays }\end{array}$ & $\begin{array}{c}\text { Prophage } \\
\text { present }\end{array}$ & $\begin{array}{l}\text { Prophage } \\
\text { ORFs }\end{array}$ \\
\hline T. melanesiensis BI429 & $\bar{Y}$ & 1879 & 424 & 33 & 80 & 37 & 5 & Yes & 49 \\
\hline T. melanesiensis 430 & & 1831 & 426 & 0 & 81 & 36 & 5 & Yes & 51 \\
\hline T. melanesiensis 431 & $\mathrm{Y}$ & 1868 & 422 & 4 & 83 & 36 & 5 & Yes & 53 \\
\hline T. melanesiensis 432 & & 1827 & 424 & 0 & 78 & 36 & 5 & Yes & 52 \\
\hline T. melanesiensis 433 & & 1832 & 424 & 0 & 82 & 36 & 5 & Yes & 51 \\
\hline T. melanesiensis 434 & & 1833 & 425 & 0 & 81 & 36 & 5 & Yes & 52 \\
\hline T. melanesiensis 487 & & 1828 & 424 & 0 & 79 & 36 & 5 & Yes & 52 \\
\hline T. affectus 1063 & Y & 1706 & 349 & 11 & 66 & 35 & 4 & & \\
\hline T. affectus 1070 & $\mathrm{Y}$ & 1765 & 351 & 43 & 71 & 35 & 4 & & \\
\hline T. affectus 1074 & & 1756 & 353 & 47 & 73 & 36 & 5 & Yes & 77 \\
\hline T. affectus ik275mar & & 1720 & 348 & 17 & 71 & 34 & 5 & & \\
\hline T. affectus 1223 & & 1726 & 349 & 68 & 76 & 32 & 5 & & \\
\hline T. africanus ob7 & & 1902 & 638 & 63 & 83 & 30 & 6 & & \\
\hline T. africanus H17ap60334 & & 1982 & 656 & 169 & 116 & 28 & 6 & Yes & 48 \\
\hline T. africanus TCF52B & $\mathrm{Y}$ & 1954 & 657 & 64 & 77 & 38 & 12 & & \\
\hline
\end{tabular}


917 Table 3. Unique gene counts per genome. Counts were obtained at the IMG database using the phylogenetic profile tool using single genes. The

918 genes of each genome were compared to the genes of all other genomes to identify genes without homologs in the reference genome, with a

919 minimum similarity of $70 \%$ and pseudogenes were excluded.

920

\begin{tabular}{|c|c|c|c|c|c|c|}
\hline Genome & $\begin{array}{l}\text { Unique } \\
\text { genes } \\
\text { (n) }\end{array}$ & $\begin{array}{c}\text { hypothetical } \\
\text { proteins }\end{array}$ & $\begin{array}{c}\text { Block } \\
>=4 \\
\text { genes }\end{array}$ & $\begin{array}{c}\text { Genes } \\
\text { per } \\
\text { block }\end{array}$ & Block CDS Ids & $\begin{array}{l}\text { Mobile Element } \\
\text { related function }\end{array}$ \\
\hline \multicolumn{7}{|c|}{ T. melanesiensis } \\
\hline BI429 & 33 & 29 & 0 & & & \\
\hline BI430 & 0 & 0 & 0 & & & \\
\hline BI431 & 4 & 1 & 0 & & & \\
\hline BI432 & 0 & 0 & 0 & & & \\
\hline BI 433 & 0 & 0 & 0 & & & \\
\hline BI434 & 0 & 0 & 0 & & & \\
\hline BI487 & 0 & 0 & 0 & & & \\
\hline \multicolumn{7}{|l|}{ T. affectus } \\
\hline BI1063 & 11 & 3 & 1 & 10 & BG95_04145 - BG95_04190 & \\
\hline BI1070 & 43 & 34 & 1 & 11 & Y592_04200 - Y592_04260 & \\
\hline \multirow[t]{3}{*}{ BI1074 } & 47 & 30 & 3 & 6 & XO08_04050 - XO08_04075 & \\
\hline & & & & 31 & XO08_07660 - XO08_07830 & Putative Prophage \\
\hline & & & & 8 & XO08_07895 - XO08_07930 & \\
\hline \multirow[t]{6}{*}{ BI1223 } & 68 & 29 & 6 & 7 & XO09_00565 - XO09_00600 & CRISPR/Cas system \\
\hline & & & & 8 & XO09_03190 - XO09_03225 & \\
\hline & & & & 11 & XO09_04035 - XO09_04085 & \\
\hline & & & & 8 & XO09_04140 - XO09_04175 & \\
\hline & & & & 15 & XO09_04205 - XO09_04275 & \\
\hline & & & & 8 & XO09_08625 - XO09_08665 & \\
\hline
\end{tabular}




\begin{tabular}{|c|c|c|c|c|c|c|}
\hline $\mathrm{ik} 275 \mathrm{mar}$ & 17 & 7 & 1 & 11 & XJ44_04105 - XJ44_04155 & 2 transposases \\
\hline \multicolumn{7}{|l|}{ T. africanus } \\
\hline \multirow[t]{10}{*}{ H17ap60334 } & 169 & 67 & 10 & 5 & H17ap60334_01201 - H17ap60334_01226 & \\
\hline & & & & 6 & H17ap60334_04767 - H17ap60334_04797 & Prophage region \\
\hline & & & & 19 & H17ap60334_04812 - H17ap60334_04902 & Prophage region \\
\hline & & & & 7 & H17ap60334_04967 - H17ap60334_04997 & Prophage region \\
\hline & & & & 6 & H17ap60334_07553 - H17ap60334_07578 & \\
\hline & & & & 17 & H17ap60334_07603 - H17ap60334_07683 & \\
\hline & & & & 31 & H17ap60334_07703 - H17ap60334_07853 & \\
\hline & & & & 6 & H17ap60334_09624 - H17ap60334_09649 & CRISPR/Cas system \\
\hline & & & & 6 & H17ap60334_10649 - H17ap60334_10674 & \\
\hline & & & & 4 & H17ap60334_11513-H17ap60334_11528 & \\
\hline \multirow[t]{4}{*}{ Ob7 } & 63 & 14 & 4 & 6 & Ob7_07340 - Ob7_07365 & \\
\hline & & & & 18 & Ob7_07400 - Ob7_07485 & \\
\hline & & & & 4 & Ob7_07685 - Ob7_07700 & \\
\hline & & & & 6 & Ob7_09642 - Ob7_09667 & \\
\hline \multirow[t]{3}{*}{ TCF52B } & 64 & 38 & 3 & 9 & THA_741 - THA_749 & \\
\hline & & & & 10 & THA_1252 THA_1261 & $\begin{array}{l}\text { Mobile element with } \\
\text { CRISPR/Cas system }\end{array}$ \\
\hline & & & & 5 & THA_1949 - THA_1953 & \\
\hline
\end{tabular}


Table 4. Overview of modification and motif analysis for three Thermosipho strains using Pacbio sequencing. Modification and motif analysis was performed using the RS_modifcation_and_motif_analysis.1 pipeline using the SMRT sequencing subreads and as a reference the non-closed

925 quiver polished HGAP assembly for each genome. Bases with m6A methylation were identified along the entire chromosome sequences of

926 Thermosipho melanesiensis 431.

\begin{tabular}{|c|c|c|c|c|c|c|c|c|}
\hline Strain & $\begin{array}{c}\text { Methylase gene } \\
\text { (Type) }\end{array}$ & Motif & $\begin{array}{c}\text { Modification } \\
\text { type }\end{array}$ & $\begin{array}{c}\text { Motifs } \\
\text { in } \\
\text { Genome }\end{array}$ & $\begin{array}{c}\text { Fraction } \\
\text { methylated } \\
\text { motifs }\end{array}$ & $\begin{array}{l}\text { mean } \\
\text { score }\end{array}$ & $\begin{array}{l}\text { Mean } \\
\text { IPD }^{\#} \\
\text { Ratio }\end{array}$ & $\begin{array}{c}\text { Mean } \\
\text { Coverage }\end{array}$ \\
\hline \multirow[t]{5}{*}{ T. melanesiensis BI431 } & BW47_01680 (II) & GATC & $\mathrm{m6A}$ & 5446 & 0,99 & 72,6 & 4,60 & 48,3 \\
\hline & BW47_02200 (I) & RTAYNNNNNNTNNCG & $\mathrm{m} 6 \mathrm{~A}$ & 520 & 0,95 & 70,6 & 5,13 & 48,0 \\
\hline & BW47_02200 (I) & CGNNANNNNNNRTAY & $\mathrm{m} 6 \mathrm{~A}$ & 520 & 0,94 & 66,9 & 4,75 & 48,5 \\
\hline & BW47_07880 (II) & CCGG & $\mathrm{m} 4 \mathrm{C}$ & 2968 & 0,71 & 45,8 & 3,63 & 49,1 \\
\hline & BW47_08940 (III) & CGCC & $\mathrm{m} 4 \mathrm{C}$ & 2462 & 0,62 & 44,6 & 3,07 & 52,3 \\
\hline T. affectus $\mathrm{BI} 1063^{\$}$ & & Not Clustered & Not applicable & 3584808 & 0,09 & 37,4 & na & 81,2 \\
\hline T. affectus. BI1070\$ & & CNNNTNCNNTAANATNG & modified base & 72 & 0,50 & 41,3 & 2,60 & 39,9 \\
\hline
\end{tabular}

*) Methylase genes are linked to the detected motif via the REBASE database predictions.

\#) IPD: Inter Pulse Density

§) Methylase gene present in the detected prophage region.

\$) Non-significant results 
932 Table 5. CRISPR array comparison of 15 Thermosipho genomes. CRISPR arrays were detected using CRISPRfinder (Grissa et al. 2007).

933 Spacers were extracted and blasted against the own genome to determine if there were other similar sequences present in the genome. Most

934 spacers that showed hits, matched other spacers found in one of the CRISPRarrays of the genome.

935

\begin{tabular}{|c|c|c|c|c|c|c|c|c|}
\hline Genome & $\begin{array}{c}\text { CRISPR } \\
\text { arrays } \\
(*)\end{array}$ & $\begin{array}{c}\text { Average } \\
\text { repeat } \\
\text { length }\end{array}$ & $\begin{array}{l}\text { Total nr } \\
\text { spacers }\end{array}$ & $\begin{array}{c}\text { average } \\
\text { number } \\
\text { of } \\
\text { spacers }\end{array}$ & $\begin{array}{l}\text { average } \\
\text { spacer } \\
\text { length }\end{array}$ & $\begin{array}{l}\text { total } \\
\text { spacer } \\
\text { length }\end{array}$ & $\begin{array}{c}\text { Spacers with } \\
\text { multiple blast hits } \\
\text { against own } \\
\text { genome }\end{array}$ & $\begin{array}{c}\text { Spacers } \\
\text { with non } \\
\text { spacer } \\
\text { blast hits }\end{array}$ \\
\hline T. melanesiensis BI429 & 5 & 30 & 94 & 18,8 & 38,96 & 3728 & 18 & 2 \\
\hline T. melanesiensis BI430 & 5 & 30 & 98 & 19,6 & 38,94 & 3882 & 18 & 2 \\
\hline T. melanesiensis $\mathrm{BI} 431$ & 5 & 30 & 98 & 19,6 & 38,94 & 3882 & 18 & 2 \\
\hline T. melanesiensis BI 432 & 5 & 30 & 98 & 19,6 & 38,94 & 3882 & 18 & 2 \\
\hline T. melanesiensis $\mathrm{BI} 433$ & 5 & 30 & 98 & 19,6 & 38,94 & 3882 & 18 & 2 \\
\hline T. melanesiensis BI434 & 5 & 30 & 97 & 19,4 & 38,92 & 3840 & 18 & 2 \\
\hline T. melanesiensis BI487 & 5 & 30 & 98 & 19,6 & 38,94 & 3882 & 18 & 2 \\
\hline T. affectus BI1063 & 4 & 31,25 & 106 & 26,5 & 37,28 & 3900 & 9 & 0 \\
\hline T. affectus BI1070 & 4 & 31,5 & 107 & 26,75 & 37,31 & 3951 & 10 & 0 \\
\hline T. affectus BI1074 & 5 & 31,2 & 58 & 11,6 & 36,58 & 2134 & 2 & 0 \\
\hline T. affectus ik275mar & 5 & 32,4 & 87 & 17,4 & 38,93 & 3315 & 7 & 1 \\
\hline T. affectus BI1223 & $4(1)$ & 31,4 & 54 & 10,8 & 38,05 & 2002 & 2 & 0 \\
\hline T. africanus ob7 & $6(1)$ & 28,9 & 106 & 15,1 & 39,33 & 4240 & 6 & 2 \\
\hline T. africanus H17ap60334 & $6(1)$ & 28,9 & 189 & 27 & 40,75 & 7628 & 19 & 8 \\
\hline T. africanus TCF52B & 12 & 30 & 321 & 26,7 & 38,73 & 12454 & 37 & 5 \\
\hline
\end{tabular}




\section{Figure legends}

941 Figure 1. Maximum Likelihood phylogeny of Thermosipho 16S rRNA sequences constructed

942 in conducted in MEGA6 (Tamura et al., 2013). The General Time Reversible (GTR) model

943 (G+I, 4 categories, (Nei \& Kumar 2000)) was used. The tree with the highest log likelihood is

944 shown. The percentage of trees in which the associated taxa clustered together is shown next

945 to the branches. Initial tree(s) for the heuristic search were obtained by applying the

946 Neighbor-Joining method to a matrix of pairwise distances estimated using the Maximum

947 Composite Likelihood (MCL) approach. The tree is drawn to scale, with branch lengths

948 measured in the number of substitutions per site, bar indicates 0.05 substitutions per site. The

949 analysis involved 61 nucleotide sequences. All positions with less than $95 \%$ site coverage

950 were eliminated. That is, fewer than $5 \%$ alignment gaps, missing data, and ambiguous bases

951 were allowed at any position. There were a total of 1245 positions in the final dataset. The

952 phylogeny is rooted using 16S rRNA gene sequences of representative sequences from other

953 Thermotogae genera (Defluviitoga, Fervidobacterium, Geotoga, Kosmotoga, Marinitoga,

954 Mesoaciditoga, Mesotoga, Oceanotoga, Petrotoga, Pseudothermotoga and Thermotoga). All

955 non-Thermosipho Thermotogales formed an outgroup and were collapsed (Supplementary

956 figure $\mathrm{S} 1$ for the full phylogeny). Thermosipho sequences are colored based on the

957 environment of isolation. Sequences with bold fonts are whole genome sequences. Triangles

958 behind the sequence ID indicate genome not from this study. Circles behind sequence ID

959 indicate genome from this study.

960

\section{Figure 2}

962 Comparison of the Thermosipho genomes based on pairwise tetranucleotide frequency

963 correlation coefficients (TETRA). Dark blue indicate highly similar genomes, while red

964 indicate low similarity. The colored lines (black, green and blue) indicate to which 
965 Thermosipho lineage/species the strains belong. The heatmap was created in R-studio using

966 pairwise TETRA values calculated with the JSpeciesWS server (Richter et al., 2015).

967

968 Figure 3

969 A) Neighbor network of the 15 Thermosipho strains. The network is based SNP's in core

970 genome fragments that were present in all genomes with a minimum of $70 \%$ similarity. The

971 network was visualized in Splitstree using the NeighborNet algorithm (Huson and Bryant,

972 2006) from uncorrected distances. B) Fraction of genes shared between 15 Thermosipho

973 genomes. Data was generated at the IMG-database using pairwise Bidirectional Best

$974 \mathrm{nSimScan}$ Hits, with genes sharing $70 \%$ sequence identity and at least $70 \%$ coverage.

975 Percentages were calculated by dividing the number shared genes by the total number of

976 genes for the genome on the y-axis. The colored lines (black, green and blue) indicated which

977 strains belong to which Thermosipho lineage/species.

978

979 Figure 4

980 Comparison of average relative COG category gene counts for three Thermosipho species. A)

981 Complete genome COG category annotations. B) Species-specific genes COG annotations.

982 COG gene annotations for each genome were summarized per category and genome counts

983 were standardized using total COG annotation counts per genomes. For the complete genome

984 COG annotations, the Kruskal-wallis test was performed on standardized counts using the

985 species clusters as groups. Categories with significant differences ( $\mathrm{p}$-value $<=0.01$ ) between

986 the species are indicated with **. The standard error of relative category counts per species, is

987 indicated by the errors bars.

988

989 Figure 5 
990 Mobile DNA defense related COG annotation counts for 15 Thermosipho isolates. A total of

99138 COGs were identified using a list of COGs related to defense genes (Makarova et al.

992 2011). The counts of the identified COGs were summarized into three groups: Restriction-

993 modification systems COGs, CRISPR-cas associated COGs, and other COGs. The strains are

994 grouped per Thermosipho species.

995 
to other Thermotogae

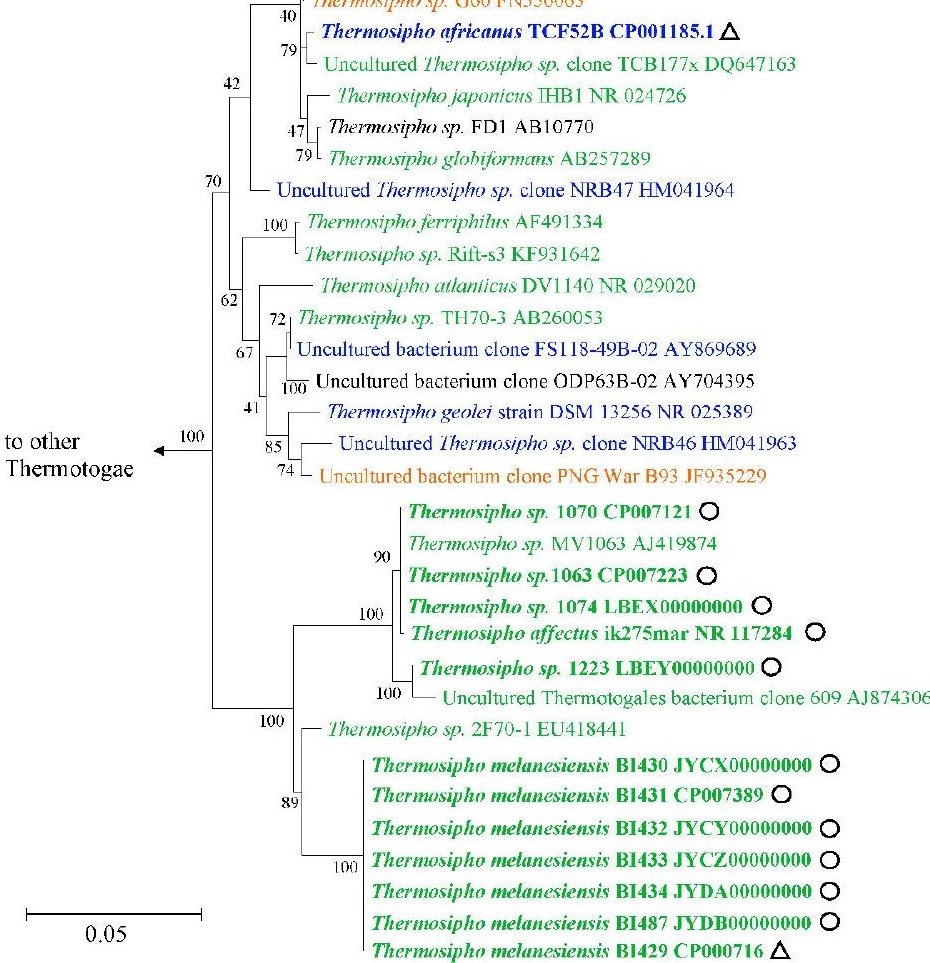




\begin{tabular}{c|c|c|c|}
0.94 & 0.96 & 0.98 \\
& \\
& TETRA
\end{tabular}

\section{Ta1223 \\ ik275mar \\ Ta1074 \\ T. affectus}

Ta1063

Ta1070

Tm432

Tm434

Tm433

Tm487

T. melanesiensis

Tm430

Tm431

Bl429

H17ap60344

TCF52B

T. africanus

Ob7

N⿴囗十

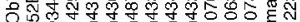

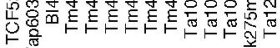
r 
T. africanus

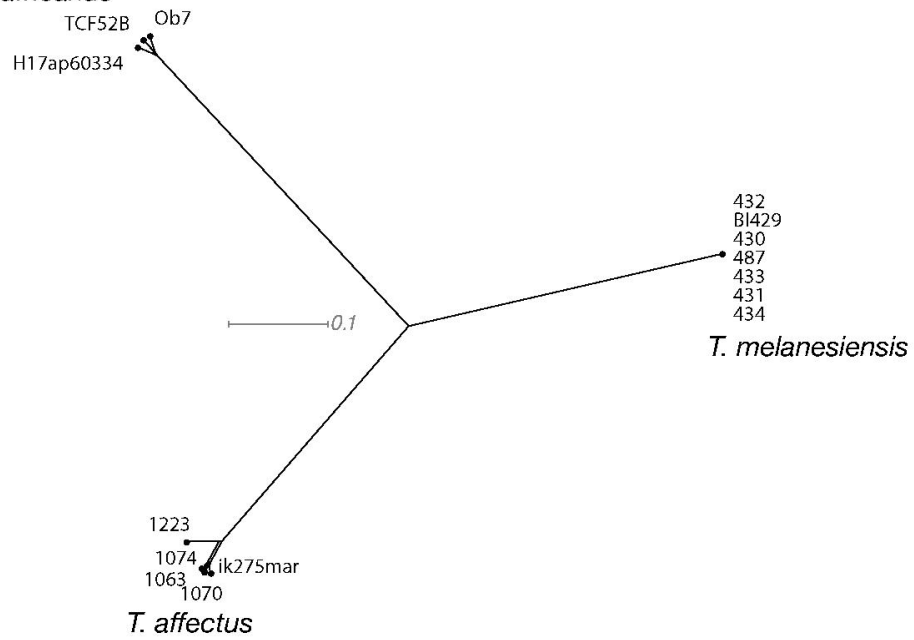

Color
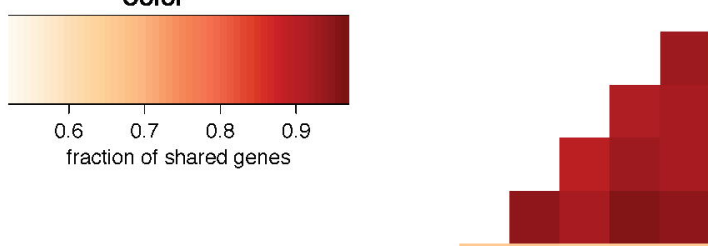

T1070

T1223

T. affectus

T1074

T1063

T434

T433

T487

T432

T. melanesiensis

T431

T430

BI429

H17ap60334

Ob7

$T$. africanus

TCF52B

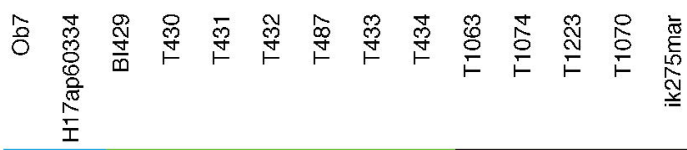




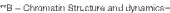

"C - Eneray productian snul nanyorzian -

'0 - Cell cycle oontrol cell dvision. chromosome partitioning

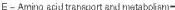

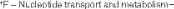

"C - Gaibdhyrate trangort and metebdism-

*H - Cosnzyme traraogrt and mebabolien-

$* 1$ - Licid trarkact and mataboliam-

"r.I - Transiation, ribosonial stuct.fu

농 arid bingaria cis

- K-Transcription-

- L - Feplication recombinajon and fepar

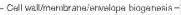

W - Col motlity-

* - Posthansational modication, proteln tumaver chanemnes $P$ - Inorgeric ion traneport. and mebaholiem

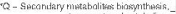
transport arid ciatabolicm

*A - General function prediction only.

s-Fungionunknown-

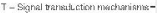

r - Intacialu Lar trallickiru. siscrotion ars Wasicu ber transport

$x-$ Deferse mechenisms

Q - Chrimán Structura ard dyrianice-

c Energy aroduction and conversion-

D Cell gyde controi, cell division, crromosome partitioning

E Mmino acid tanspoit and metabolism-

F- duckintick ransparl arid mulaboriani-

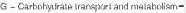

H Coenzume ranspot and metaboism-

Lipid ransport and metabolism-

J- Trandaliorı. ribosuma giruciura

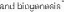

K- Tientiridion -

Teclicalion recomangtion. andrekeir

OH Cell wallinembrave'erkelope kiogenese-

N-Cell noblity-

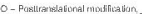
protein tumover, chapercres-

$\Gamma$ Iruganic isc tansport and metabolism

Q Secondary metabolines bicsynthesis, La rispicirl ard calabdiani-

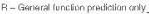

$$
\text { G - Funcliont untemoun- }
$$

T Signd trunaduct on mechenisms-

U Intracelular tratt cking secretion and vesicular trareor.-

$v$ - Dalixtzs maxihanifrne -

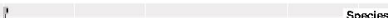

T. imelsnesfensis
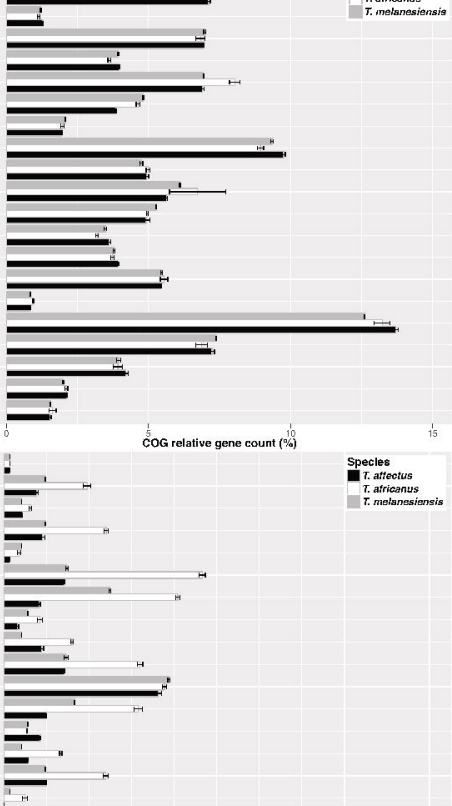

H

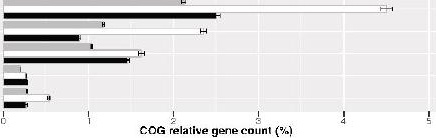

COG relative gene count (\%) 
$40-$

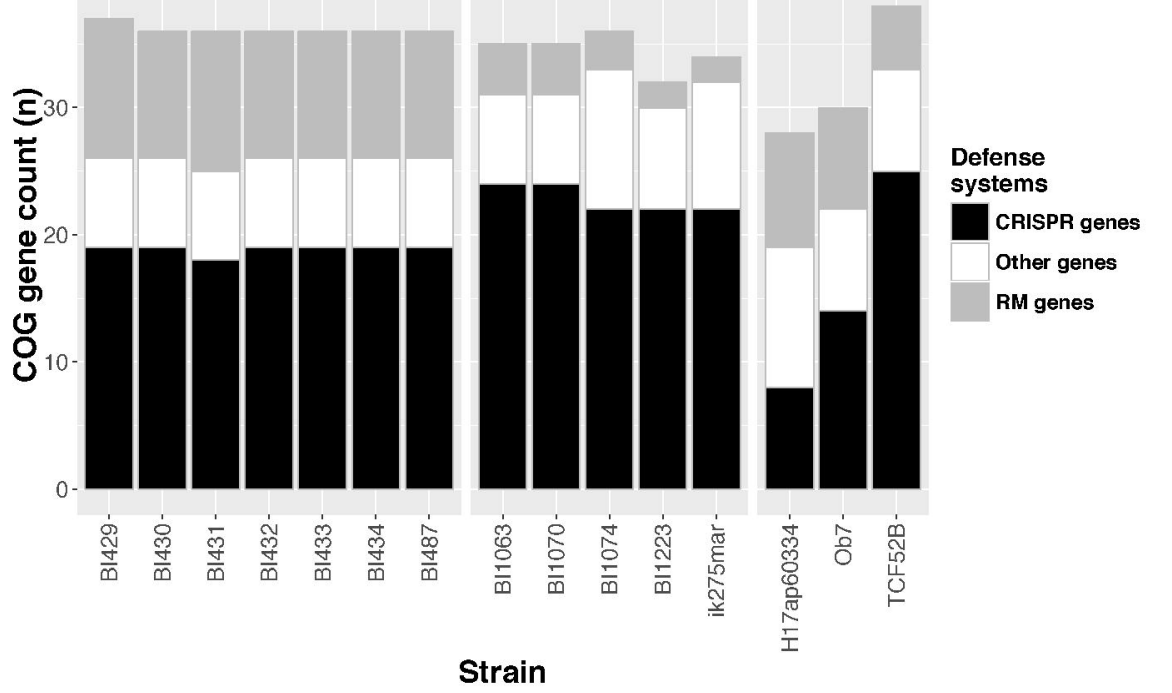

